\title{
The role of diffuse correlation spectroscopy and frequency-domain near-infrared spectroscopy in monitoring cerebral hemodynamics during hypothermic circulatory arrests
}

Alexander I. Zavriyev, BS, ${ }^{\text {a }}$ Kutlu Kaya, MS, ${ }^{\text {a }}$ Parisa Farzam, PhD, ${ }^{\text {a }}$ Parya Y. Farzam, BS, John Sunwoo, PhD, ${ }^{a}$ Arminder S. Jassar, MBBS, ${ }^{b}$ Thoralf M. Sundt, MD, ${ }^{b}$ Stefan A. Carp, PhD, ${ }^{a}$ Maria Angela Franceschini, $\mathrm{PhD},{ }^{\mathrm{a}}$ and Jason Z. Qu, $\mathrm{MD}^{\mathrm{c}}$

\section{ABSTRACT}

Objectives: Real-time noninvasive monitoring of cerebral blood flow (CBF) during surgery is key to reducing mortality rates associated with adult cardiac surgeries requiring hypothermic circulatory arrest (HCA). We explored a method to monitor cerebral blood flow during different brain protection techniques using diffuse correlation spectroscopy (DCS), a noninvasive optical technique which, combined with frequency-domain near-infrared spectroscopy (FDNIRS), also provides a measure of oxygen metabolism.

Methods: We used DCS in combination with FDNIRS to simultaneously measure hemoglobin oxygen saturation $\left(\mathrm{SO}_{2}\right)$, an index of cerebral blood flow $\left(\mathrm{CBF}_{\mathrm{i}}\right)$, and an index of cerebral metabolic rate of oxygen $\left(\mathrm{CMRO}_{2 \mathrm{i}}\right)$ in 12 patients undergoing cardiac surgery with HCA.

Results: Our measurements revealed that a negligible amount of blood is delivered to the cerebral cortex during HCA with retrograde cerebral perfusion, indistinguishable from $\mathrm{HCA}$-only cases (median $\mathrm{CBF}_{\mathrm{i}}$ drops of $93 \%$ and $95 \%$, respectively) with consequent similar decreases in $\mathrm{SO}_{2}$ (mean decrease of $0.6 \pm 0.1 \%$ and $0.9 \pm 0.2 \%$ per minute, respectively); $\mathrm{CBF}_{\mathrm{i}}$ and $\mathrm{SO}_{2}$ are mostly maintained with antegrade cerebral perfusion; the relationship of $\mathrm{CMRO}_{2 i}$ to temperature is given by $\mathrm{CMRO}_{2 \mathrm{i}}=0.052 \mathrm{e}^{0.079 \top}$.

Conclusions: FDNIRS-DCS is able to detect changes in $\mathrm{CBF}_{\mathrm{i}}, \mathrm{SO}_{2}$, and $\mathrm{CMRO}_{2 \mathrm{i}}$ with intervention and can become a valuable tool for optimizing cerebral protection during HCA. (JTCVS Techniques 2021;7:161-77)

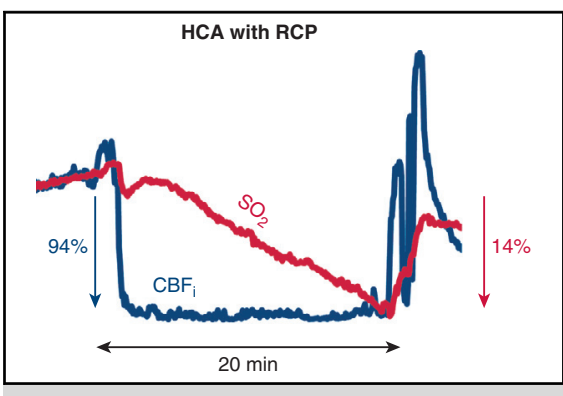

Blood flow index drops to 0 at HCA with RCP. Oxygenation decreases $0.7 \%$ per minute.

CENTRAL MESSAGE

Intraoperative DCS monitoring could offer insights into the effectiveness of different cerebral-protection methods in delivering blood flow to the brain during circulatory arrest.

\section{PERSPECTIVE}

Monitoring of cerebral blood flow index and hemoglobin oxygen saturation in cardiac surgery requiring HCA is possible with combined FDNIRS-DCS. We show that RCP may be inadequate whereas ACP could overcompensate in blood flow delivery to the cerebral cortex. Further studies are needed to confirm the role of FDNIRS-DCS in guiding optimization of cerebral blood perfusion to improve neurologic outcomes.

See Commentaries on pages 178 and 180.

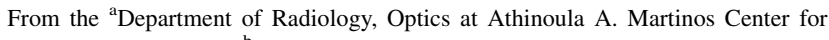
Biomedical Imaging, bivision of Cardiac Surgery, Corrigan Minehan Heart Center, and ${ }^{\mathrm{c}}$ Department of Anesthesia, Critical Care and Pain Medicine, Massachusetts General Hospital, Harvard Medical School, Boston, Mass.

This work is supported by National Institutes of Health R01GM116177 and R01HD091067 (M.A.F.) and R01NS100750 (S.A.C.).

Received for publication Jan 18, 2021; accepted for publication Jan 19, 2021; available ahead of print Jan 29, 2021.
Address for reprints: Alexander I. Zavriyev, BS, 149 13th St, Charlestown, MA 02129 (E-mail: azavriyev@mgh.harvard.edu). 2666-2507

Copyright $(\subset) 2021$ The Authors. Published by Elsevier Inc. on behalf of The American Association for Thoracic Surgery. This is an open access article under the CC BY-NCND license (http://creativecommons.org/licenses/by-nc-nd/4.0/).

https://doi.org/10.1016/j.xjtc.2021.01.023 


\section{Abbreviations and Acronyms \\ $\mathrm{ACP}=$ antegrade cerebral perfusion \\ $\mathrm{CBF}_{\mathrm{i}}=$ cerebral blood flow (index) \\ $\mathrm{CMRO}_{2 \mathrm{i}}=$ cerebral metabolic rate of oxygen (index) \\ $\mathrm{CPB}=$ cardiopulmonary bypass \\ DCS = diffuse correlation spectroscopy \\ EEG = electroencephalography \\ FDNIRS $=$ frequency-domain near-infrared spectroscopy \\ HCA = hypothermic circulatory arrest \\ NIRS = near-infrared spectroscopy \\ $\mathrm{RCP} \quad=$ retrograde cerebral perfusion \\ $\mathrm{rSO}_{2}=$ regional oxygen saturation \\ $\mathrm{SO}_{2}=$ hemoglobin oxygen saturation \\ $\mathrm{TCD}=$ transcranial Doppler ultrasound}

Video clip is available online.

Neurologic injury is one of the most dreaded complications in cardiac surgery. Maintenance of optimal brain blood flow during cardiac surgery is an essential part of ensuring patients' neurologic health. Among the cardiac surgical procedures, those imposing the greatest risk of neurologic injury include procedures requiring episodes of circulatory arrest. Hypothermia has been the mainstay of the surgical strategies to prevent cerebral ischemic injury during circulatory arrest (ie, hypothermic circulatory arrest $[\mathrm{HCA}])^{1}$ by lowering the brain's metabolic rate. Moderate $\left(20.1^{\circ} \mathrm{C}\right.$ $\left.28^{\circ} \mathrm{C}\right)$ and deep $\left(14.1^{\circ} \mathrm{C}-20^{\circ} \mathrm{C}\right)$ hypothermia levels help minimize neurologic injury. ${ }^{2,3}$ However, hypothermia alone doesn't always provide sufficient brain protection, as shown by the relatively high mortality rates during aortic arch surgeries. ${ }^{4}$ Thus, during HCA it has become common clinical practice to provide cerebral blood perfusion. The most common methods are retrograde and antegrade cerebral perfusion (RCP and ACP, respectively). ${ }^{5}$ During RCP, cold blood is delivered to the brain via retrograde flow in the venous system through a cannula placed in the superior vena cava, to ensure delivery of blood to the brain parenchyma. In selective ACP, the brain is perfused in an antegrade fashion via the arterial system, often unilaterally through the right axillary or innominate artery.

There is ongoing discussion regarding the best perfusion strategy for optimal neuroprotection during HCA. ${ }^{6-8}$ This is partially due to the complexity of clinical assessment of the impact of strategies on neurologic function as an end point and also to the limited ability to directly monitor cerebral blood flow noninvasively. In animal models, invasive approaches have demonstrated that RCP delivers much less blood to the cortex than ACP. ${ }^{9,10}$ These findings have not yet been thoroughly validated in cardiac surgery patients. Currently available techniques for noninvasive intraoperative brain monitoring in procedures include electroencephalography (EEG), cerebral oximetry, and transcranial Doppler ultrasound (TCD). While providing insights into brain protection efficacy in real time, these monitoring techniques each presents limitations. During deep HCA, EEG is used to ensure that hypothermia and anesthesia are maintaining complete suppression of electrical activity. ${ }^{11}$ While EEG measures neuronal activity, it does not provide a direct measure of oxygen metabolism, the biomarker that hypothermia acts on. Cerebral oximetry using near-infrared spectroscopy (NIRS) estimates regional hemoglobin oxygen saturation $\left(\mathrm{rSO}_{2}\right)$ in the brain, ${ }^{12}$ but it cannot distinguish between $\mathrm{rSO}_{2}$ changes due to oxygen availability versus consumption. A drop in NIRS readings may indicate inadequate cerebral blood flow (CBF), but it could also indicate sustained oxygen consumption as a result of insufficient hypothermia or anesthesia. TCD is a powerful technique that measures blood flow velocity in the large basal arteries of the brain. ${ }^{13}$ However, TCD is not done routinely during HCA because of the requirement of stable positioning and alignment that needs to be done by a trained operator. ${ }^{14}$

Diffuse correlation spectroscopy (DCS) is a noninvasive optical technique that provides an index of cerebral blood flow $\left(\mathrm{CBF}_{\mathrm{i}}\right)$ and has been shown to effectively monitor blood flow in cardiac surgical procedures in neonates. ${ }^{15-17}$ DCS makes use of the speckle interference pattern formed when coherent light travels through a scattering medium. The pattern perturbs as the scatterers drift, and computing the intensity autocorrelation function $\mathrm{g}_{2}(\tau)$ estimates the velocity of moving scatterers. ${ }^{18}$ Since red blood cells form the overwhelming majority of moving scatterers in tissue, DCS provides an index of blood flow in the illuminated tissue (ie, scalp, skull, and brain).

Several studies have validated $\mathrm{CBF}_{\mathrm{i}}$ measures against gold standards, ${ }^{19-23}$ and it holds promise for differentiating pathologic conditions in adults. ${ }^{24,25}$ DCS measurements are conducted via a flexible lightweight patch probe that doesn't disturb the patient, and monitoring can be done continuously during surgery. Further, it is possible to use both NIRS and DCS synergistically to, in addition to $\mathrm{CBF}_{\mathrm{i}}$ and $\mathrm{SO}_{2}$, acquire an index of cerebral metabolic rate of oxygen (index) $\left(\mathrm{CMRO}_{2 \mathrm{i}}\right)$, a more comprehensive measure of brain health. ${ }^{26}$ Simultaneous monitoring of these 3 biomarkers offers a comprehensive guide for optimizing brain protection during adult cardiac surgery with HCA.

In this study, we use a hybrid instrument combining frequency-domain near-infrared spectroscopy (FDNIRS) and DCS $^{26}$ to monitor cerebral perfusion and oxygen 
metabolism during HCA procedures in an adult population (study outlined in Figure 1). This work demonstrates the feasibility of acquiring $\mathrm{SO}_{2}, \mathrm{CBF}_{\mathrm{i}}$, and $\mathrm{CMRO}_{2 \mathrm{i}}$ changes noninvasively during surgery and highlights the differences in cerebral perfusion delivered during HCA-only, RCP, and ACP.

\section{METHODS}

\section{Subjects}

We enrolled 12 patients ( 7 male, mean age $61.8 \pm 19.4$ years) scheduled to undergo elective cardiac surgery with use of circulatory arrest between February 2017 and December 2019 at the Massachusetts General Hospital. Potential patients for HCA were approached during their preoperative visit. The study was explained to the patients by a physician, and they had until the day of the surgery to decide whether to participate and sign the informed consent. This study was reviewed and approved by the Partners Healthcare Human Research Committee (institutional review board \#2016P001944; approved November 11, 2016).

Table 1 outlines the patients' demographic and intraoperative characteristics. Four patients underwent HCA-only, 3 RCP, and 5 ACP. The 3 groups were not randomized, and the choice of protection method was based on patients' disease and surgeons' preferences.

\section{FDNIRS-DCS Device}

For these measurements, we used a commercial combined FDNIRS-DCS system, MetaOx (ISS Inc, Champaign, Ill). Details about this device can be found in Carp and colleagues, and in Video $1 .{ }^{26}$ In 4 subjects, only the DCS component was used, and in the rest both DCS and FDNIRS data were acquired simultaneously. The DCS component employed a single $35 \mathrm{~mW}, 850 \mathrm{~nm}$ laser and 8 single-photon avalanche detectors. The FDNIRS component included eight 2-mW lasers of wavelength ranging between 670 and $830 \mathrm{~nm}$, and 4 photomultiplier tube detectors. The fiber-optic probe used is shown in Figure 2.

\section{Experimental Procedure}

Electrocardiogram, pulse oximetry, cerebral oximetry (INVOS 5100c; Medtronic [Minneapolis, Minn]; present in 7 patients), nasopharyngeal temperature, and intra-arterial blood pressure were obtained from the Epic (Verona, Wis) electronic medical record system. These signals were co-registered with our data at one point per minute resolution. Arterial blood pressure was also collected directly with our device at $10 \mathrm{~Hz}$. The optical probe was positioned on the patient's forehead after induction of general anesthesia. We secured the probe several centimeters above the eyebrow and used surgical tape to secure the probe to the patient. Data collection began immediately after anesthesia induction and ended after chest closure.

\section{Using FDNIRS-DCS to measure real time cerebral perfusion during hypothermic circulatory arrests}
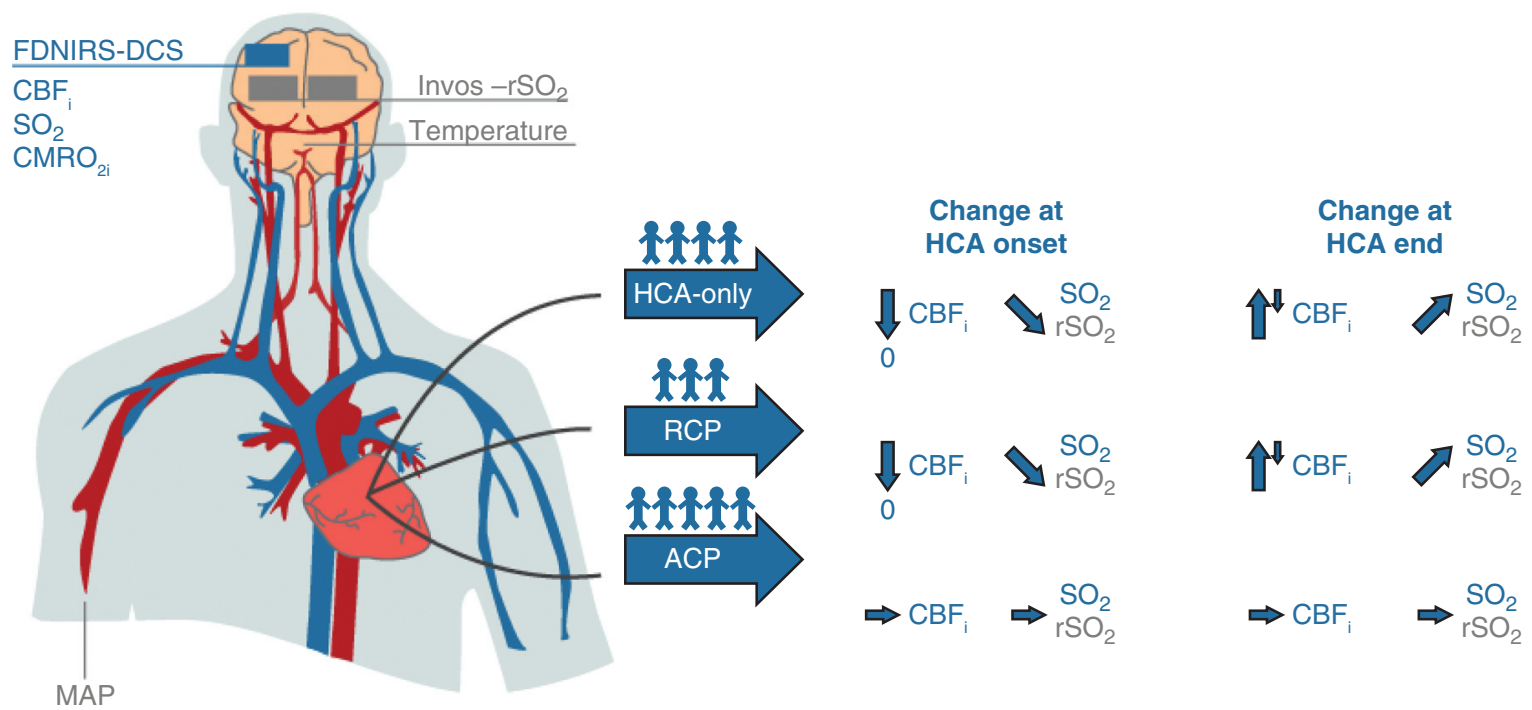

HCA - Hypothermic circulatory arrest; RCP - Retrograde cerebral perfusion; ACP - Antegrade cerebral perfusion;

FDNIRS-DCS - Frequency domain near infrared spectroscopy - diffuse correlation spectroscopy; CPB - Cardiopulmonary bypass; $\mathrm{CBF}_{\mathrm{i}}$ - Cerebral blood flow index; (r)SO2 - (relative) cerebral oxygen saturation; $\mathrm{CMRO}_{2 \mathrm{i}}-\mathrm{Cerebral}_{\text {metabolic rate }}$ of oxygen; MAP - Mean arterial pressure

FIGURE 1. Real-time noninvasive cerebral blood flow monitoring during cardiac surgery could help optimize neuroprotective measures and hence decrease rates of neurologic injury associated with $\mathrm{HCA}$. We used combined FDNIRS-DCS to measure hemoglobin $\mathrm{SO}_{2}, \mathrm{CBF}_{\mathrm{i}}$, and $\mathrm{CMRO}_{2 \mathrm{i}}$ in 12 adults undergoing HCA (4 HCA-only, $3 \mathrm{RCP}, 5 \mathrm{ACP}$ ). We coacquired $\mathrm{rSO}_{2}$ from a hospital oximeter (INVOS; Medtronic, Minneapolis, Minn), MAP, and nasopharyngeal temperature. Our measurements revealed that during $\mathrm{HCA}$ with $\mathrm{RCP}_{\mathrm{CBF}}$ drops to almost zero and overshoots above baseline when circulation is restarted, similar to the $\mathrm{CBF}_{\mathrm{i}}$ behavior found during $\mathrm{HCA}$-only. As a consequence of the low perfusion, with $\mathrm{RCP}$ and $\mathrm{HCA}^{-o n l y ~} \mathrm{SO}_{2}$ decreases during $\mathrm{HCA}$; on in contrast, both $\mathrm{CBF}_{\mathrm{i}}$ and $\mathrm{SO}_{2}$ are mostly maintained with ACP. FDNIRS-DCS, Frequency domain near-infrared spectroscopy and diffuse correlation spectroscopy; $C B F_{i}$, cerebral blood flow index; $\mathrm{SO}_{2}$, oxygen saturation; $\mathrm{CMRO}_{2 i}$, cerebral metabolic rate of oxygen; $r \mathrm{SO}_{2}$, regional oxygen saturation; $H C A$, hypothermic circulatory arrest; $R C P$, retrograde cerebral perfusion; $A C P$, antegrade cerebral perfusion; $M A P$, mean arterial blood pressure. 
TABLE 1. Demographics and intraoperative data of measured patients

\begin{tabular}{|c|c|c|c|c|c|c|c|c|c|}
\hline No. & Age, $y$ & Sex & Operative procedure & $\begin{array}{l}\text { Avg HCA } \\
\text { temp, }{ }^{\circ} \mathrm{C}\end{array}$ & $\begin{array}{l}\text { Cerebral } \\
\text { perfusion }\end{array}$ & HCA length & $\begin{array}{c}\text { Optical } \\
\text { modality }\end{array}$ & INVOS & $\begin{array}{c}\text { Monitoring } \\
\text { duration }\end{array}$ \\
\hline 1 & 57 & M & $\begin{array}{r}\text { Valve-sparing aortic root } \\
\text { replacement }+ \text { AAHR }\end{array}$ & $23.2 \pm 0.2$ & HCA-only & $12 \mathrm{~m}$ & DCS & No & $3 \mathrm{~h}, 30 \mathrm{~min}$ \\
\hline 2 & 78 & M & $\begin{array}{l}\mathrm{CABG} \times 3+\mathrm{AVR}+\text { ascending } \\
\text { aortic replacement }\end{array}$ & $16.8 \pm 0.2$ & HCA-only & $25 \mathrm{~m}$ & DCS & No & $4 \mathrm{~h}, 52 \mathrm{~min}$ \\
\hline 3 & 59 & $\mathrm{~F}$ & $\begin{array}{l}\text { Right pulmonary } \\
\text { thromboendarterectomy }+ \text { left } \\
\text { lower lobe wedge resection }\end{array}$ & $\begin{array}{l}19.6 \pm 0.1 \\
19.4 \pm 0.03\end{array}$ & HCA-only & $19 \mathrm{~m}, 12 \mathrm{~m}$ & FDNIRS-DCS & Yes & $4 \mathrm{~h}, 44 \mathrm{~min}$ \\
\hline 4 & 87 & $\mathrm{~F}$ & $\begin{array}{l}\mathrm{AVR}+\mathrm{CABG} \times 1+ \\
\text { pulmonary vein } \\
\text { isolation }+\mathrm{LAA} \\
\text { ligation }+\mathrm{AAHR}\end{array}$ & $20.3 \pm 0.2$ & HCA-only & $29 \mathrm{~m}$ & FDNIRS-DCS* & Yes & $6 \mathrm{~h}, 56 \mathrm{~min}$ \\
\hline 5 & 26 & M & $\begin{array}{r}\text { Valve-sparing aortic root } \\
\text { replacement + AAHR }\end{array}$ & $17.9 \pm 0.1$ & $\mathrm{RCP}$ & $17 \mathrm{~m}$ & DCS & No & $8 \mathrm{~h}, 02 \mathrm{~min}$ \\
\hline 6 & 85 & $\mathrm{~F}$ & $\begin{array}{l}\text { AVR + pulmonary vein } \\
\text { isolation + LAA } \\
\text { ligation + AAHR }\end{array}$ & $18.4 \pm 0.1$ & $\mathrm{RCP}$ & $21 \mathrm{~m}$ & FDNIRS-DCS & Yes & $5 \mathrm{~h}, 33 \mathrm{~min}$ \\
\hline 7 & 38 & M & $\mathrm{AVR}+\mathrm{AAHR}$ & $18.2 \pm 0.1$ & $\mathrm{RCP}$ & $22 \mathrm{~m}$ & FDNIRS-DCS & Yes & $5 \mathrm{~h}, 30 \mathrm{~min}$ \\
\hline 8 & 77 & M & $\mathrm{AVR}+\mathrm{AAHR}$ & $24.9 \pm 0.1$ & $\mathrm{ACP}$ & $20 \mathrm{~m}$ & DCS & No & $6 \mathrm{~h}, 53 \mathrm{~min}$ \\
\hline 9 & 49 & $\mathrm{~F}$ & $\mathrm{AVR}+\mathrm{AAHR}$ & $27.1 \pm 0.1$ & $\mathrm{ACP}$ & $14 \mathrm{~m}$ & FDNIRS-DCS & No & $4 \mathrm{~h}, 26 \mathrm{~min}$ \\
\hline 10 & 67 & M & AAHR & $22.0 \pm 0.7$ & $\mathrm{ACP}$ & $20 \mathrm{~m}$ & FDNIRS-DCS & Yes & $3 \mathrm{~h}, 57 \mathrm{~min}$ \\
\hline 11 & 45 & M & $\begin{array}{l}\text { Redo sternotomy }+ \text { total arch } \\
\text { replacement }\end{array}$ & $20.2 \pm 0.1$ & $\mathrm{ACP}$ & $48 \mathrm{~m}$ & FDNIRS-DCS & Yes & $5 \mathrm{~h}, 57 \mathrm{~min}$ \\
\hline 12 & 73 & M & $\begin{array}{l}\text { Redo } \\
\quad \text { sternotomy }+\mathrm{AVR}+\mathrm{CABG} \times 4 \\
\quad+\text { ascending aortic }+ \text { Zone I } \\
\text { aortic arch replacement }\end{array}$ & $18.8 \pm 0.1$ & ACP & $47 \mathrm{~m}$ & FDNIRS-DCS* & Yes & $10 \mathrm{~h}, 35 \mathrm{~min}$ \\
\hline
\end{tabular}

Monitoring duration started immediately after anesthesia induction and ended after the procedure concluded. Patient 3 had 2 circulatory arrests. In 8 patients, we used combined FDNIRS-DCS, and only DCS in 4. Seven patients had bilateral cerebral oximetry (INVOS) acquired clinically. RCP flow rate was maintained at 300-400 mL/min to target a CVP of 20-25 mm Hg. Circulatory arrest time refers to the length of time the cardiopulmonary bypass flow to the heart was stopped (with or without cerebral perfusion). HCA, Hypothermic circulatory arrest; $M$, male; $A A H R$, ascending aortic and hemiarch replacement; $D C S$, diffuse correlation spectroscopy; $C A B G$, coronary artery bypass grafting; $A V R$, aortic valve replacement; $F$, female; FDNIRS, frequency-domain near-infrared spectroscopy; $L A A$, left atrial appendage; $R C P$, retrograde cerebral perfusion with HCA; $A C P$, antegrade cerebral perfusion with HCA. *Interference with the INVOS made it so FDNIRS data are only available discontinuously.

\section{Signal Processing and Analysis}

Both DCS and FDNIRS signals were down-sampled from 10 to $0.2 \mathrm{~Hz}$. FDNIRS raw data signal artifacts due to interference from the INVOS cerebral oximeter were removed during preprocessing (for more detail, see the Appendix 1). To compute the absorption and scattering coefficients of measured tissue, we used the frequency-domain multidistance method. ${ }^{27}$ From the absorption coefficient, we estimated $\mathrm{SO}_{2}$. Blood flow index at each source-detector separation was obtained from the DCS data using the semi-infinite medium correlation diffusion equation. ${ }^{18}$ Fixed absorption and reduced scattering coefficients at $850 \mathrm{~nm}\left(0.11 \mathrm{~cm}^{-1}\right.$ and $8.5 \mathrm{~cm}^{-1}$, respectively) obtained averaging across all the subjects measured with FDNIRS, were used to quantify changes in $\mathrm{CBF}_{\mathrm{i}}$ with $\mathrm{HCA}$. Actual optical properties were used to calculate absolute $\mathrm{CBF}_{\mathrm{i}}$ in 6 patients with continuous FDNIRS data.

$\mathrm{CMRO}_{2 \mathrm{i}}$ before and after HCA was calculated using Fick's Principle ${ }^{28}$ (details available in the Appendix 1), and because of the need for measured optical properties to quantify $\mathrm{CBF}_{\mathrm{i}}$ and $\mathrm{SO}_{2}$, only the 6 patients with continuous FDNIRS data were included in this analysis.

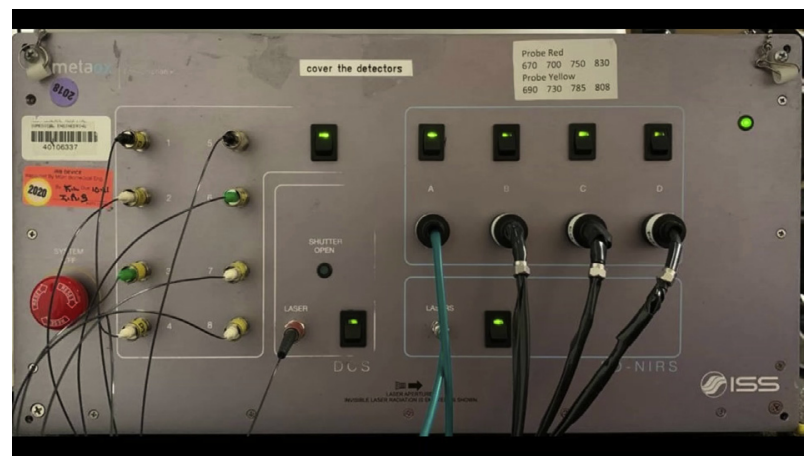

VIDEO 1. Dr Jason Qu and Alexander Zavriyev discuss the relevance of the study for the cardiac surgery community and introduce the current stage of the research device. Ultimately, this exploratory study could lead to a large-scale study directly correlating cerebral hemodynamics with patient outcomes in hypothermic circulatory arrests. Video available at: https://www.jtcvs.org/article/S2666-2507(21)00093-6/fulltext. 

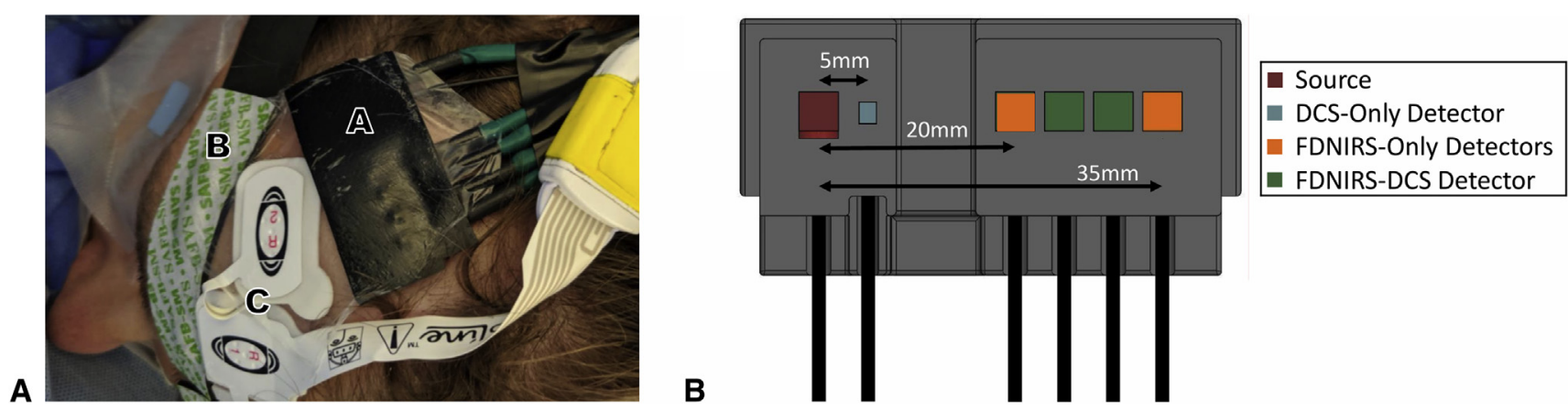

FIGURE 2. A, Photograph of our optical probe on a patient: $A=$ FDNIRS-DCS optical probe, $B=$ hospital INVOS oximeter probe, $\mathrm{C}=$ processed electroencephalogram probe. B, Schematic of the FDNIRS-DCS probe. NIRS and DCS light source fibers (dark red square) are colocalized and diffused over a 3.5-mm spot diameter to meet American National Standards Institute standard irradiance limits. A DCS short separation detector fiber (light blue) is located $5 \mathrm{~mm}$ from the source center and used to detect scalp blood flow. Remaining DCS detector fibers (green) were located at 25 and $30 \mathrm{~mm}$ from the source for greater sensitivity to cerebral blood flow. For patients that also had FDNIRS measurements, in addition to the colocalized 25- and 30-mm detector fibers, we had 2 detector fibers located at 20 and $35 \mathrm{~mm}$ from the source, except for patient 9 , where the 2 extra detectors were at 15 and $20 \mathrm{~mm}$ from the source. Multiple separations in FDNIRS allow for application of the multidistance method to calculate $\mathrm{SO}_{2}$. Note: our probe is small and lightweight and doesn't requires special training to correctly operate. FDNIRS-DCS, Frequency domain near-infrared spectroscopy and diffuse correlation spectroscopy.

\section{Statistical Analysis}

All statistical analyses were carried out using IBM SPSS (version 25.0; IBM Corp, Armonk, NY). Using a one-way analysis of variance test, we compared the ratio of $\mathrm{CBF}_{\mathrm{i}}$ and $\mathrm{SO}_{2}$ during versus pre-HCA among the 3 groups, followed by a Dunnett T3 post hoc test for pairwise comparisons.
To reveal the relationship between $\mathrm{CMRO}_{2 \mathrm{i}}$ and temperature, a Pearson correlation test was performed. Statistical significance was evaluated by using a one-tail $t$-distribution table with a $95 \%$ confidence interval (lower bound: 0.134, upper bound: 0.806). Data are reported as mean \pm standard deviation unless stated otherwise, and $P<.05$ was

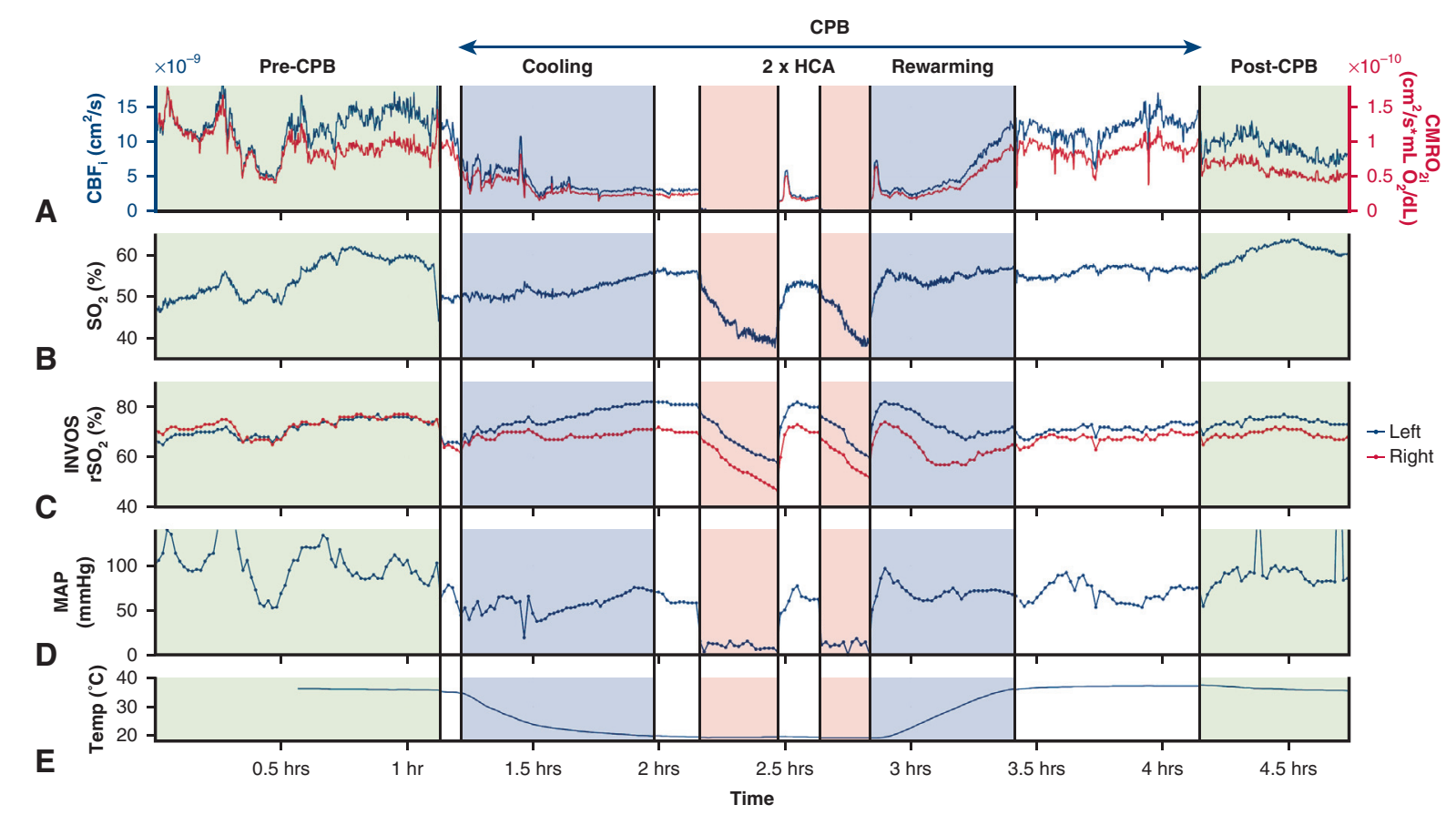

FIGURE 3. Full measurement of a patient (3) during a pulmonary thromboendarterectomy with 2 periods of HCA without any additional perfusion (HCAonly). $\mathrm{CBF}_{\mathrm{i}}$, (A, blue, left axis), $\mathrm{CMRO}_{2 \mathrm{i}}\left(\mathrm{A}\right.$, red, right axis), and hemoglobin oxygenation $\left(\mathrm{SO}_{2}, \mathrm{~B}\right)$ are measured by our combined FDNIRS-DCS device. The remaining 3 panels show the INVOS $\mathrm{rSO}_{2}$ measured in the left $(\mathrm{C}$, blue $)$ and right $(\mathrm{C}$, red $)$ forehead, MAP as measured via an arterial cannula in the arm (D), and temperature measured with a nasopharyngeal probe (E) throughout the surgery. In sections shaded in light green, the patient's heart is driving blood circulation. In all other sections, the patient is on CPB. Noteworthy trends include the high correlation between $\mathrm{CBF}_{\mathrm{i}}, \mathrm{CMRO}_{2 \mathrm{i}}$, and temperature; the immediate measured drop to zero of the $\mathrm{CBF}_{\mathrm{i}}$ at the beginning of each HCA, followed by the sharp overshoots at the end of HCA; and finally, the high correlation between $\mathrm{SO}_{2}$ measurements taken via FDNIRS and the INVOS oximeter. $C B F_{i}$, Cerebral blood flow index; $C P B$, cardiopulmonary bypass; $H C A$, hypothermic circulatory arrest; $\mathrm{CMRO}_{2 i}$, cerebral metabolic rate of oxygen; $\mathrm{SO}_{2}$, oxygen saturation; $r \mathrm{SO}_{2}$, regional oxygen saturation; $M A P$, mean arterial pressure. 


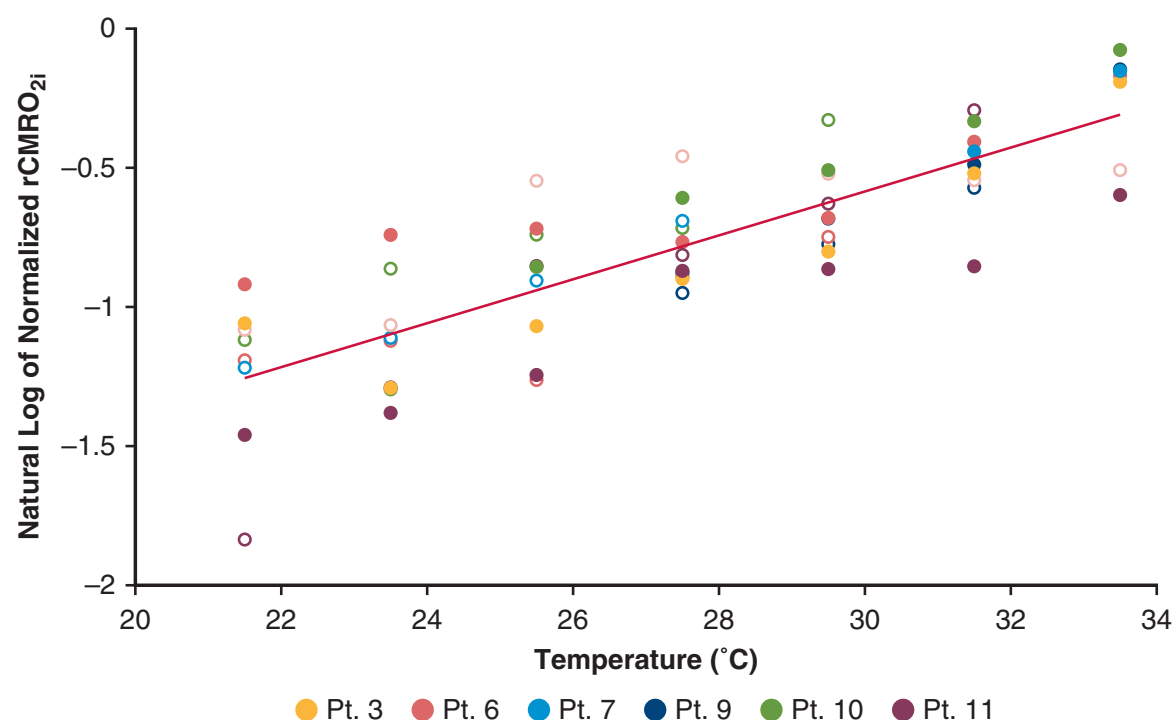

FIGURE 4. $\mathrm{Log}$ of the normalized $\mathrm{CMRO}_{2 \mathrm{i}}$ versus temperature in 6 patients who had continuous FDNIRS-DCS measurements. Each patient is indicated by a different color. Open markers indicate cooling periods and filled markers indicate rewarming periods. Each patient's $\mathrm{CMRO}_{2 \mathrm{i}}$ values are normalized with respect to average $\mathrm{CMRO}_{2 \mathrm{i}}$ between $34.5^{\circ} \mathrm{C}$ and $36.5^{\circ} \mathrm{C}$ during patient rewarming. The red line is the linear fit, which demonstrates the expected temperature linear dependence. Pearson correlation coefficient $\mathrm{r}=0.84$, statistically significant at the .01 level. $C M R O_{2 i}$, Cerebral metabolic rate of oxygen; FDNIRS$D C S$, frequency domain near-infrared spectroscopy and diffuse correlation spectroscopy.

considered significant. The temporal correlation between FDNIRS-DCS and physiological measures was calculated using an in-house MATLAB pipeline using the corrcoef function.

\section{RESULTS}

The average total HCA time across subjects was $24 \pm 12$ minutes. The average nasopharyngeal temperatures in patients during $\mathrm{HCA}$-only, RCP, and ACP were $19.9 \pm 2.3^{\circ} \mathrm{C}, 18.1 \pm 0.3^{\circ} \mathrm{C}$, and $22.6 \pm 3.4^{\circ} \mathrm{C}$, respectively.

\section{$\mathrm{CBF}_{\mathrm{i}}, \mathrm{CMRO}_{2 \mathrm{i}}$, and $\mathrm{SO}_{2}$ Perioperative Monitoring}

Figure 3 shows a characteristic measurement of a patient undergoing HCA-only from start to finish (patient 3). We identified 6 phases: precardiopulmonary bypass (CPB), $\mathrm{CPB}$, cooling, HCA, rewarming, and post-CPB. A wide range in $\mathrm{CBF}_{\mathrm{i}}$ (Figure $3, A$, left axis) can be seen throughout the surgery. Under $\mathrm{CPB}$ and cooling, $\mathrm{CBF}_{\mathrm{i}}$ decreases substantially following the temperature decrease (Figure 3, $E$ ), whereas $\mathrm{SO}_{2}$ (Figure 3, B) remains constant, consistent with the reduction in $\mathrm{CMRO}_{2 \mathrm{i}}$ (Figure 3, $A$, right axis). The most drastic change in $\mathrm{CBF}_{\mathrm{i}}$ and $\mathrm{SO}_{2}$ happens during circulatory arrest. This patient underwent 2 HCAs with no perfusion, and on both occasions $\mathrm{CBF}_{\mathrm{i}}$ dropped to near zero within 30 seconds and $\mathrm{SO}_{2}$ gradually decreased at an average rate of $1 \%$ per minute. The FDNIRS $\mathrm{SO}_{2}$ and the INVOS $\mathrm{rSO}_{2}$ (Figure 3, $C$ ) show differences in the absolute values due to the different assumptions made with the 2 devices, but exhibit the same trends.

Across all subjects, the average correlation between FDNIRS $\mathrm{SO}_{2}$ and the INVOS $\mathrm{rSO}_{2}$ was $0.8 \pm 0.1$. On average, the correlation coefficient between $\mathrm{CBF}_{\mathrm{i}}$ and mean arterial pressure was weak $(0.3 \pm 0.2, P<.01)$. We also did not find any significant correlation between $\mathrm{CBF}_{\mathrm{i}}$ and $\mathrm{SO}_{2}$ (correlation coefficient $-0.2 \pm 0.4, P<.01$ ). Both $\mathrm{CBF}_{\mathrm{i}}$ and $\mathrm{CMRO}_{2 \mathrm{i}}$ were strongly positively related with temperature during cooling and rewarming periods (correlation coefficient $0.9 \pm 0.1, P<.01$ for both).

Figure 4 shows the temperature dependency of $\mathrm{CMRO}_{2 \mathrm{i}}$ normalized with respect to the rewarming $35.5^{\circ} \mathrm{C}$ value. Each data point represents the average $\mathrm{CMRO}_{2 \mathrm{i}}$ values for the cooling/rewarm periods at the temperature value $\pm 1^{\circ} \mathrm{C}$. Points during HCA were excluded. Since linear fits during cooling and rewarming were nearly identical, we combined them into one fit. The relationship between the natural log of normalized $\mathrm{CMRO}_{2 \mathrm{i}}$ and temperature is described by the linear function: $=0.08 \mathrm{~T}-$ 3.0 (correlation coefficient $=0.8, P<.01$ ).

\section{$\mathrm{CBF}_{\mathrm{i}}$ and $\mathrm{SO}_{2}$ Behavior at Circulatory Arrest}

Figure 5 shows the $\mathrm{CBF}_{\mathrm{i}}$ and $\mathrm{SO}_{2}$ time traces for an HCA-only case, an RCP case, and an ACP case, focusing on the period of HCA. These 3 representative cases highlight the cerebrovascular dynamics observed during the 3 procedures. In HCA-only and $\mathrm{RCP}, \mathrm{CBF}_{\mathrm{i}}$ dropped sharply to near zero at HCA onset and overshot at the end of $\mathrm{HCA}$. At the same time, $\mathrm{SO}_{2}$ gradually decreased during HCA and after HCA gradually recovered. With ACP, $\mathrm{CBF}_{\mathrm{i}}$, and $\mathrm{SO}_{2}$ were maintained to values close to pre-HCA.

To examine cerebral perfusion and oxygenation changes during circulatory arrest, we quantified the ratios of $\mathrm{CBF}_{\mathrm{i}}$ and changes in $\mathrm{SO}_{2}$ during versus pre-HCA for each patient 

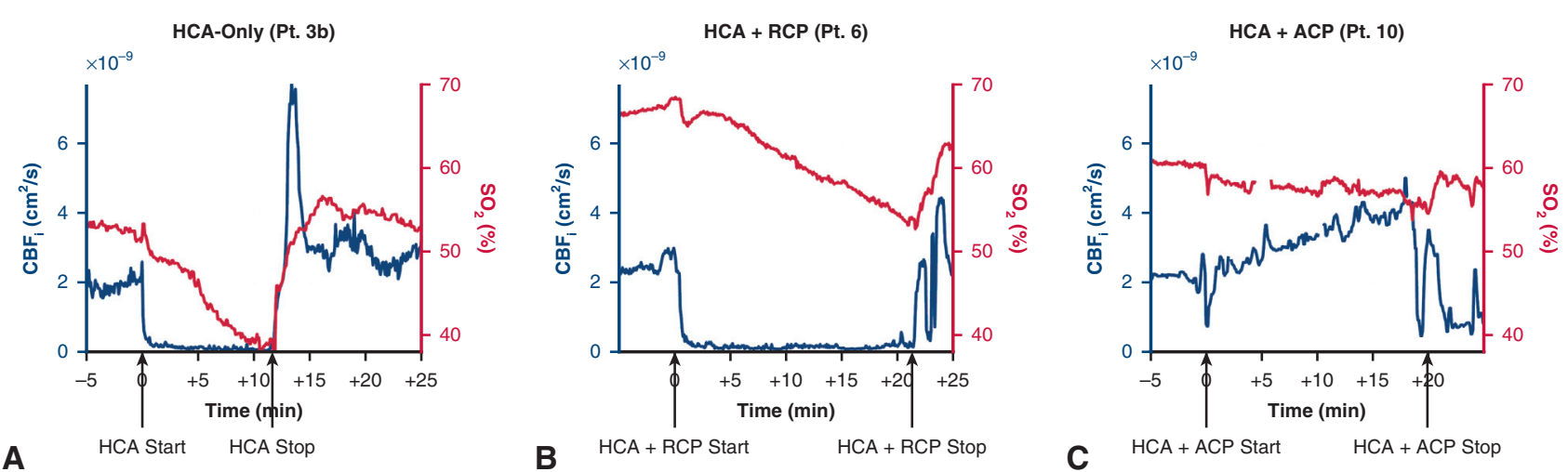

FIGURE 5. $\mathrm{CBF}_{\mathrm{i}}$ (blue, left axis) and hemoglobin $\mathrm{SO}_{2}$ (red, right axis) measured by our combined FDNIRS-DCS device. A, Patient 3 during the second $\mathrm{HCA}$ with no extra perfusion (HCA-only). $\mathrm{CBF}_{\mathrm{i}}$ dropped $94 \pm 3 \%$ within the first minute of $\mathrm{HCA}$. The patient's $\mathrm{SO}_{2}$ decreased by $14 \pm 1 \%$ over the $12-$ minute $\mathrm{HCA}\left(1.2 \pm 0.1 \%\right.$ per minute). B, Patient 6 , who underwent $\mathrm{HCA}$ with RCP. $\mathrm{CBF}_{\mathrm{i}}$ dropped $93 \pm 3 \%$ within the first minute of $\mathrm{HCA} \mathrm{SO} \mathrm{S}_{2}$ dropped at a slower rate $(0.7 \%$ per minute) than the HCA-only patient and dropped by $23 \pm 1 \%$ after 20 minutes of HCA. C, Patient 10 , who underwent HCA with ACP. At the beginning of $\mathrm{ACP}, \mathrm{CBF}_{\mathrm{i}}$ is at the pre-HCA level, but it increases throughout the procedure, ultimately reaching 2 times the initial level (mean increase of $57 \pm 39 \%) . \mathrm{SO}_{2}$, in contrast, did not demonstrate this increase of perfusion, instead dropping through the procedure by $4.6 \%\left(\mathrm{SO}_{2}\right.$ drop-rate of $0.1 \pm 0.2 \%$ per minute). It is notable that cerebral perfusion does not increase during an RCP procedure. This was indicated by $\mathrm{CBF}_{\mathrm{i}}$ more promptly than $\mathrm{SO}_{2}$ signal. Furthermore, HCA-only and RCP cases display a large overshoot at reperfusion that is identifiable only in the $\mathrm{CBF}_{\mathrm{i}}$ time trace. $C B F_{i}$, Cerebral blood flow index; $H C A$, hypothermic circulatory arrest; $\mathrm{SO}_{2}$, oxygen saturation; $\mathrm{RCP}$, retrograde cerebral perfusion; $A C P$, antegrade cerebral perfusion.

(Figure 6). Patients who received HCA-only experienced a $\mathrm{CBF}_{\mathrm{i}}$ median drop of $95 \%$ (range, $94 \%-98 \%$ ) and patients receiving RCP experienced a median drop of $93 \%$ (range, $87 \%-94 \%$ ), whereas patients receiving ACP experienced a median increase in $\mathrm{CBF}_{\mathrm{i}}$ of $+3 \%$ (range: $12 \%$ to $+58 \%$ ). There was a statistically significant difference in the ratio of $\mathrm{CBF}_{\mathrm{i}}$ during versus pre-HCA among the 3 cerebral-protection methods $\left(F_{2,10}=51.75, P=.001\right)$. We confirmed the significantly lower $\mathrm{CBF}_{\mathrm{i}}$ ratio in HCAonly $(0.05 \pm 0.01)$ and $\mathrm{RCP}(0.08 \pm 0.03)$ cases with respect to ACP $(1.1 \pm 0.3)$ cases, with statistically significant mean differences of $P=.003$. There were no statistically significant differences between the $\mathrm{CBF}_{\mathrm{i}}$ drops in HCA-only and RCP cases $(P=.5)$.

Figure 6, $B$, reports the $\mathrm{SO}_{2}$ drop at the end of HCA with respect to pre-HCA and Figure 6, $C$, reports the drop-rate in the 8 patients that had FDNIRS measurements. The $\mathrm{SO}_{2}$ total drops and drop-rates for HCA-only and HCA with RCP cases were similar, with total mean drops of $18 \pm 4 \%$ (mean drop-rates of $0.9 \pm 0.2 \%)$ in HCA-only and $13 \%(0.6 \%)$ in RCP. Meanwhile, HCA with ACP mostly maintained $\mathrm{SO}_{2}$ throughout the HCA, with a mean total drop of $3 \pm 2 \%$ and a mean drop-rate of $0.2 \pm 0.2 \%$ per minute.

We also quantified the overshoots at the end of circulatory arrest with respect to the post-HCA recovery values. The median $\mathrm{CBF}_{\mathrm{i}}$ overshoots in the HCA-only and RCP cases were 2.4 (range, 1.8-2.9) and 2.6 (range, 1.8-3.3) times greater than recovery levels, respectively. There were no significant overshoots in the ACP cases and no overshoot of $\mathrm{SO}_{2}$ in any cases.

\section{DISCUSSION}

This is the first report using FDNIRS-DCS to evaluate the changes in $\mathrm{CBF}_{\mathrm{i}}$ and hemoglobin oxygenation throughout 3 common brain-protection strategies in adult cardiac surgery with HCA. In the 30 years since deep HCA $\left(<20^{\circ} \mathrm{C}\right)$ was first successfully introduced during aortic arch surgery, clinical outcomes have improved significantly. ${ }^{29}$ However, aortic arch surgery is still associated with a high incidence of neurologic complications, including permanent and temporary neurologic dysfunctions. ${ }^{30}$ EEG and NIRS are often used as intraoperative brain-monitoring tools to optimize individual protection strategies during HCA. And while these modalities provide valuable information to the surgical team, they cannot directly assess the cerebral blood perfusion provided by ACP and RCP. This stimulated us to employ DCS, which is an easy-to-use method that allows continuous and noninvasive monitoring of an index of cerebral blood flow.

\section{Utility of $\mathrm{CBF}_{\mathrm{i}}$ and $\mathrm{SO}_{2}$ Measures in HCA-Only and HCA With RCP Procedures}

The rationale of RCP is to provide metabolic support, maintaining brain hypothermia while preventing embolism. One question concerning this technique is whether the brain tissue receives enough blood. The efficacy of RCP to provide nutritive brain perfusion has been challenged by a few invasive studies in animals ${ }^{9,10}$ and nonhuman primates, ${ }^{31}$ demonstrating a low and uneven distribution of blood flow to the brain, especially in the cortex. We were able to reproduce these results in humans, noninvasively 

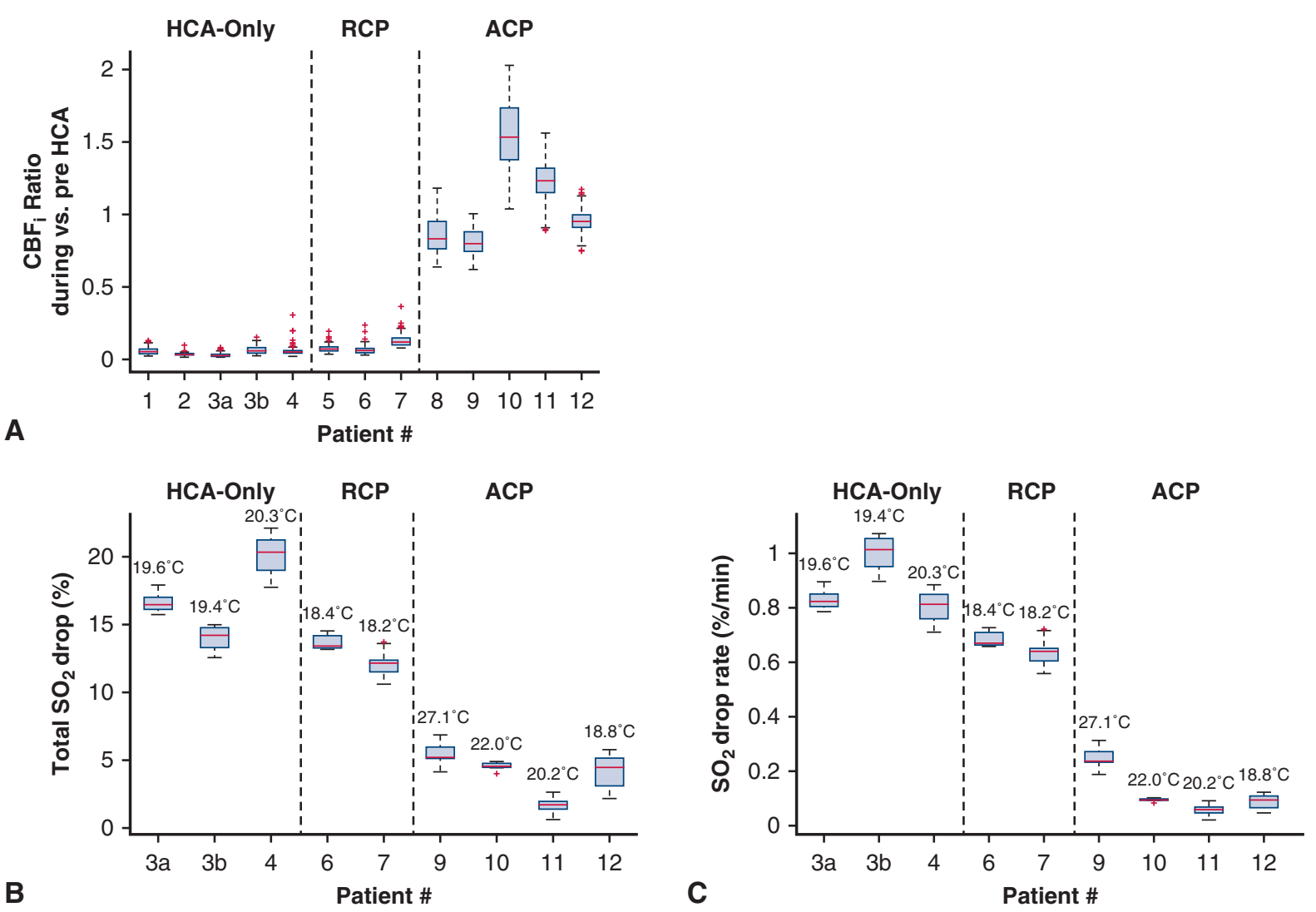

FIGURE 6. Relative changes in $\mathrm{CBF}_{\mathrm{i}}$ and hemoglobin $\mathrm{SO}_{2}$ during $\mathrm{HCA}$ versus pre-HCA baseline with different brain-protection procedures (HCA-only, $\mathrm{RCP}, \mathrm{ACP}$ ). All data are presented in box and whisker format. The red line indicates the median, the edges of the box indicate the 25 th and 75 th percentiles, the whiskers extend to the extreme nonoutlier data points, and outliers are represented as red addition symbols. A, The ratios of $\mathrm{CBF}_{\mathrm{i}}$ during versus pre-HCA measured with DCS. Pre-HCA interval was identified as 5-minute period immediately before HCA start (with one exception, patient 2, where we had to use a 2-minute period because of artifacts). During-HCA was defined as the average from 1 minute into HCA to the HCA stop time. B, Percent drop of $\mathrm{SO}_{2}$ measured with FDNIRS. Values were averaged for 60 seconds for both the pre-HCA baseline and end of HCA values. Numbers above bars indicate average temperature during HCA. C, Average drop-rate of $\mathrm{SO}_{2}$ through HCA. HCA durations were determined using electronic records and are precise to the minute time scale. Notice that for (A), there is no significant difference between $\mathrm{CBF}_{\mathrm{i}}$ drops in $\mathrm{HCA}$-only and $\mathrm{RCP}$ cases, and both are significantly different from ACP cases. Furthermore, as we would expect, in (B) and (C) HCA-only and RCP have similar $\mathrm{SO}_{2}$ drops and drop rates, whereas ACP drops are significantly lower. These differences would likely be made even more striking when accounting for the differences in body temperatures, which are considerably greater in patients undergoing ACP than those who are undergoing HCA-only and RCP. $C B F_{i}$, Cerebral blood flow index; $H C A$, hypothermic circulatory arrest; $R C P$, retrograde cerebral perfusion; $A C P$, antegrade cerebral perfusion; $\mathrm{SO}_{2}$, oxygen saturation.

with DCS. The negligible amount of blood flow we detected during RCP may suggest the efficacy of RCP as a neuroprotective method may be only partial and attributed to mechanisms other than flushing of emboli and provision of nutrients. ${ }^{29}$ The minimal perfusion during RCP is consistent with the reduction in $\mathrm{SO}_{2}$ that we measured in these patients, which is very similar to the reductions observed in patients receiving HCA-only.

Our results also show a $\mathrm{CBF}_{\mathrm{i}}$ overshoot in patients with HCA-only and HCA with RCP when cerebral blood flow was restored at the end of circulatory arrest, which was not observed in patients undergoing HCA with ACP. This hyperperfusion did not show up in $\mathrm{SO}_{2}$ monitoring. The mechanism and potential consequences of these transient hyperperfusion events in HCA patients are unknown. In carotid endarterectomy and in carotid angioplasty with stenting, a similar reperfusion is known to cause cerebral hyperperfusion syndrome, a rare but severe complication characterized by headaches, neurologic deficits, and seizures. ${ }^{32}$ The rapid and large $(140 \%$ above post-HCA recovery) increase of blood flow in patients with HCA-only and RCP may put them at a similar risk. FDNIRS and DCS monitoring during HCA-only and HCA with RCP may allow surgeons to adjust CPB flow to minimize the cerebral hyperperfusion circulation is resumed and the end of HCA.

\section{$\mathrm{CBF}_{\mathrm{i}}$ and $\mathrm{SO}_{2}$ in $\mathrm{HCA}$ With ACP Procedure}

Because it provides oxygenated blood in a more physiological manner, ACP has become more popular than RCP 
over the past 15 years. Most surgeons choose the right axillary artery for ACP, titrating ACP flow to a pressure of 50 to $70 \mathrm{~mm} \mathrm{Hg}$ and flow of 6 to $10 \mathrm{~mL} / \mathrm{kg} / \mathrm{m}$ to provide adequate brain perfusion. ${ }^{33}$ However, these established flow rates are largely based on the empiric data and retrospective studies, with no direct cerebral perfusion measurements supporting it. Also, older patients may have a partially degraded circle of Willis, potentially compromising contralateral brain perfusion. ${ }^{34}$ If the contralateral $\mathrm{SO}_{2}$ levels drop during HCA with ACP, the clinicians may ask to raise perfusion pressure or increase CPB flow to facilitate left brain hemisphere perfusion. This can raise ipsilateral brain blood flow without improving contralateral perfusion. DCS could be a valuable tool to warn if flow is not reaching the contralateral side and to detect high flow ipsilaterally. In the current study, we were able to monitor only one side, and in $1 \mathrm{pa}-$ tient (10), we saw a large increase of $\mathrm{CBF}_{\mathrm{i}}$ in the right hemisphere and a drop in INVOS $\mathrm{rSO}_{2}$ in the left side (see Figure E3). Both FDNIRS and INVOS failed to detect a significant increase is $\mathrm{SO}_{2}$ in the ipsilateral side. It is plausible that in this patient the circle of Willis was unable to perfuse the contralateral side during ACP. This kind of situation poses the patient both at risk of stroke in the hypoperfused left hemisphere as well at risk of postoperative delirium if luxury perfusion is sustained in the right hemisphere. ${ }^{33,35,36}$

A bilateral measurement of $\mathrm{CBF}_{i}$ would allow monitoring of ACP efficacy in both brain hemispheres and help identify patients who will benefit from institution of bilateral cerebral perfusion. Moreover, because of the heterogenicity of patients undergoing surgeries with $\mathrm{HCA}$, a direct measure of $\mathrm{CBF}_{\mathrm{i}}$ could be used to individualize adjustment of ACP flow rates for each patient. Further studies are needed to confirm that regulating blood flow with DCS could provide better brain protection and allow optimization of ACP flow rates during HCA.

\section{Temperature Dependence of $\mathrm{CMRO}_{2 \mathrm{i}}$}

Reliable monitoring of $\mathrm{CMRO}_{2}$ during cooling is crucial to achieving the target metabolic reduction with hypothermia. With our noninvasive $\mathrm{CMRO}_{2 \mathrm{i}}$ measurements, we found a linear relationship between the $\log$ of $\mathrm{CMRO}_{2}$ and temperature $(0.08 \mathrm{~T}-3)$ similar to that measured by Croughwell and colleagues ${ }^{37}$ with a xenon-clearance method $(0.11 \mathrm{~T}-3.83)$.

The advantage of our DCS measurements resides in the ability to measure continuously, and, more importantly, the fact that it uses nonionizing radiation (light), as opposed to the positron emission tomography method's need of a radioactive tracer. Ko and colleagues ${ }^{38}$ have observed differences in $\mathrm{CMRO}_{2 \mathrm{i}}$ temperature dependence during cooling and rewarming in an HCA neonatal swine model, finding significantly lower $\mathrm{CMRO}_{2 \mathrm{i}}$ values after rewarming. We, however, found the same $\mathrm{CMRO}_{2 \mathrm{i}}$ relationship during cooling and rewarming, with $\mathrm{CMRO}_{2 \mathrm{i}}$ returning to the precooling levels after rewarming. Differences in these results are likely due to differences in experimental procedures. Our results are also in agreement with our previous work, where DCS was used at 5 discrete timepoints during $\mathrm{CPB}$ in infants. ${ }^{20}$

\section{Study Limitations and Additional Comments}

One of the limitations of this pilot study is small number of patients recruited. Another limitation of our study is the lack of bilateral measurements, which is particularly interesting when ensuring bilateral brain perfusion during unilateral ACP. It is worth noting the disparity between the $\mathrm{SO}_{2}$ values measured by the INVOS versus FDNIRS. The IN$\mathrm{VOS} \mathrm{rSO}_{2}$ shows greater values and drops than the FDNIRS values, likely because of the strong assumptions made with the continuous wave device. ${ }^{39}$ Nevertheless, the correlation between the 2 measurements is very high.

The measured $\mathrm{CBF}_{\mathrm{i}}$ during HCA-only does not reach absolute zero. While in normal physiological states, DCS measurements are driven by red blood cell movement, when blood flow is stopped, the residual thermal (Brownian) motion will result in a nonzero DCS perfusion estimate. This Brownian motion contribution is $\sim 1 \%$ of the signal in normal conditions and relevant only when $\mathrm{CBF}_{\mathrm{i}}$ drops more than $90 \%$ from physiological levels.

DCS, like in NIRS, brings the challenge of ensuring that the signals are representative of the brain and not the scalp. We acquired data at both short and large separations, and these signals were compared to determine the sensitivity of the large separation to cerebral blood flow. In all data sets, we observed differences in relative signal changes between the short and long separations. Also, expecting brain blood flow to be greater than scalp blood flow, in 10 of our 12 measurements we observed larger $\mathrm{CBF}_{\mathrm{i}}$ values in the long separations, with some periods reporting almost 2 times the value of the short separation. We therefore believe that our longer separations are sensitive to the brain blood flow. For the 2 measurements (IDs 1 and 6) where the short separation blood flow index was greater, we believe the probe may have been placed directly over or near to a superficial vessel, causing short separation DCS to report greater than normal flow. The conclusions of our data analysis did not change based on the inclusion or exclusion of these 2 data sets, so we kept both in our analysis.

\section{CONCLUSIONS}

We have shown that combined DCS and FDNIRS provide new useful information during cardiac surgical procedures using circulatory arrest. In particular, DCS reliably measures $\mathrm{CBF}_{\mathrm{i}}$ and identifies periods of brain hypoperfusion and hyperperfusion, as shown in the low $\mathrm{CBF}_{\mathrm{i}}$ values measured during RCP, and its overshoot at the end of the procedure, similar to the values measured during HCAonly. Variability of $\mathrm{CBF}_{\mathrm{i}}$ levels across patients during 
ACP reflect important individual differences. Overall, DCS alone or combined with NIRS can potentially guide brain protection to help clinicians achieve patient-tailored optimal brain perfusion.

\section{Conflict of Interest Statement}

M.A.F. has financial interest in 149 Medical, Inc, a company developing DCS technology for assessing and monitoring cerebral blood flow in newborn infants, and in Dynometrics, Inc, a company that makes devices that use NIRS technology for athletes to evaluate muscle performance. M.A.F. interests were reviewed and are managed by Massachusetts General Hospital and Mass General Brigham $(\mathrm{f} / \mathrm{k} / \mathrm{a} /$ Partners HealthCare) in accordance with their conflict-of-interest policies. M.A.F. has a patent related to aspects of FDNIRS used in this manuscript. M.A.F. and S.A.C. have patent applications pending on aspects of the DCS technology used in this manuscript. All other authors reported no conflicts of interest.

The Journal policy requires editors and reviewers to disclose conflicts of interest and to decline handling or reviewing manuscripts for which they may have a conflict of interest. The editors and reviewers of this article have no conflicts of interest.

The authors thank Dr Felipe Orihuela-Espina for help with statistical analysis, as well as Dr Duke E. Cameron and Dr Serguei Melnitchouk for their contributions in performing the surgeries and offering clinical insight. We also thank Zack Starkweather for designing the optical probes and Adriano Peruch for device designs. Thank you to Robert Petrosyan for drawing and editing the Graphical Abstract. Finally, thank you to Juliette Selb, Melissa Wu and Vidhya V. Nair for their contributions to data acquisition.

\section{References}

1. Mezrow CK, Sadeghi AM, Gandsas A, Dapunt OE, Shiang HH, Zappulla RA, et al. Cerebral effects of low-flow cardiopulmonary bypass and hypothermic circulatory arrest. Ann Thorac Surg. 1994;57:532-9.

2. Wypij D, Newburger JW, Rappaport LA, duPlessis AJ, Jonas RA, Wernovsky G, et al. The effect of duration of deep hypothermic circulatory arrest in infant heart surgery on late neurodevelopment: the Boston circulatory arrest trial. J Thorac Cardiovasc Surg. 2003;126:1397-403.

3. Gaynor JW, Nicolson SC, Jarvik GP, Wernovsky G, Montenegro LM, Burnham NB, et al. Increasing duration of deep hypothermic circulatory arrest is associated with an increased incidence of postoperative electroencephalographic seizures. J Thorac Cardiovasc Surg. 2005;130:1278-86.

4. Czerny M, Fleck T, Zimpfer D, Dworschak M, Hofmann W, Hutschala D, et al. Risk factors of mortality and permanent neurologic injury in patients undergoing ascending aortic and arch repair. J Thorac Cardiovasc Surg. 2003;126: 1296-301.

5. Englum BR, He X, Gulack BC, Ganapathi AM, Mathew JP, Brennan JM, et al. Hypothermia and cerebral protection strategies in aortic arch surgery: a comparative effectiveness analysis from the STS adult cardiac surgery database. Eur J Cardiothorac Surg. 2017;52:492-8.

6. Elefteriades JA. What is the best method for brain protection in surgery of the aortic arch? Straight DHCA. Cardiol Clin. 2010;28:381-7.

7. Bachet J. What is the best method for brain protection in surgery of the aortic arch? Selective antegrade cerebral perfusion. Cardiol Clin. 2010;28:389-401.

8. Ueda Y. What is the best method for brain protection in surgery of the aortic arch? Retrograde cerebral perfusion. Cardiol Clin. 2010;28:371-9.
9. Ehrlich MP, Hagl C, McCullough JN, Zhang N, Shiang H, Bodian C, et al. Retrograde cerebral perfusion provides negligible flow through brain capillaries in the pig. J Thorac Cardiovasc Surg. 2001;122:331-8.

10. Fukae K, Nakashima A, Hisahara M, Kawachi Y, Masuda M, Yasui H. Maldistribution of the cerebral blood flow in retrograde cerebral perfusion. Eur J Cardiothorac Surg. 1995;9:491-6.

11. Mizrahi EM, Patel VM, Crawford ES, Coselli JS, Hess KR. Hypothermic induced electrocerebral silence, prolonged circulatory arrest, and cerebral protection during cardiovascular surgery. Electroencephalogr Clin Neurophysiol 1989;72:81-5.

12. Shin'oka T, Nollert G, Shum-Tim D, du Plessis A, Jonas RA. Utility of nearinfrared spectroscopic measurements during deep hypothermic circulatory arrest. Ann Thorac Surg. 2000;69:578-83.

13. Purkayastha S, Sorond F. Transcranial Doppler ultrasound: technique and application. Semin Neurol. 2012;32:411-20.

14. Naqvi J, Yap KH, Ahmad G, Ghosh J. Transcranial Doppler ultrasound: a review of the physical principles and major applications in critical care. Int J Vasc Med. 2013;2013:629378.

15. Dehaes M, Cheng HH, Buckley EM, Lin P-Y, Ferradal S, Williams K, et al. Perioperative cerebral hemodynamics and oxygen metabolism in neonates with single-ventricle physiology. Biomed Opt Express. 2015;6:4749-67.

16. Durduran T, Zhou C, Buckley EM, Kim MN, Yu G, Choe R, et al. Optical measurement of cerebral hemodynamics and oxygen metabolism in neonates with congenital heart defects. J Biomed Opt. 2010;15:37004.

17. Buckley EM, Hance D, Pawlowski T, Lynch J, Wilson FB, Mesquita RC, et al. Validation of diffuse correlation spectroscopic measurement of cerebral blood flow using phase-encoded velocity mapping magnetic resonance imaging. J Biomed Opt. 2012;17:37007.

18. Durduran T, Choe R, Baker WB, Yodh AG. Diffuse optics for tissue monitoring and tomography. Rep Prog Phys. 2010;73:076701.

19. Busch DR, Rusin CG, Miller-Hance W, Kibler K, Baker WB, Heinle JS, et al. Continuous cerebral hemodynamic measurement during deep hypothermic circulatory arrest. Biomed Opt Express. 2016;7:3461-70.

20. Ferradal SL, Yuki K, Vyas R, Ha CG, Yi F, Stopp C, et al. Non-invasive assessment of cerebral blood flow and oxygen metabolism in neonates during hypothermic cardiopulmonary bypass: feasibility and clinical implications. Sci Rep. 2017; 7:44117.

21. Milej D, He L, Abdalmalak A, Baker WB, Anazodo UC, Diop M, et al. Quantification of cerebral blood flow in adults by contrast-enhanced near-infrared spectroscopy: validation against MRI. J Cereb Blood Flow Metab. 2020;40:1672-84.

22. Giovannella M, Andresen B, Andersen JB, El-Mahdaoui S, Contini D, Spinelli L, et al. Validation of diffuse correlation spectroscopy against (15)O-water PET for regional cerebral blood flow measurement in neonatal piglets. J Cereb Blood Flow Metab. 2020;40:2055-65.

23. Jain V, Buckley EM, Licht DJ, Lynch JM, Schwab PJ, Naim MY, et al. Cerebral oxygen metabolism in neonates with congenital heart disease quantified by MRI and optics. J Cereb Blood Flow Metab. 2014;34:380-8.

24. Baker WB, Balu R, He L, Kavuri VC, Busch DR, Amendolia O, et al. Continuous non-invasive optical monitoring of cerebral blood flow and oxidative metabolism after acute brain injury. J Cereb Blood Flow Metab. 2019;39:1469-85.

25. Selb J, Wu K-C, Sutin J, Lin P-YI, Farzam P, Bechek S, et al. Prolonged monitoring of cerebral blood flow and autoregulation with diffuse correlation spectroscopy in neurocritical care patients. Neurophotonics. 2018;5:45005.

26. Carp SA, Farzam P, Redes N, Hueber DM, Franceschini MA. Combined multidistance frequency domain and diffuse correlation spectroscopy system with simultaneous data acquisition and real-time analysis. Biomed Opt Express. 2017;8:3993-4006.

27. Fantini S, Franceschini MA, Fishkin JB, Barbieri B, Gratton E. Quantitative determination of the absorption spectra of chromophores in strongly scattering media: a light-emitting-diode based technique. Appl Opt. 1994;33:5204-13.

28. Roche-Labarbe N, Carp SA, Surova A, Patel M, Boas DA, Grant PE, et al. Noninvasive optical measures of $\mathrm{CBV}, \mathrm{StO}(2), \mathrm{CBF}$ index, and $\mathrm{rCMRO}(2)$ in human premature neonates' brains in the first six weeks of life. Hum Brain Mapp. 2010;31:341-52.

29. Geube M, Sale S, Svensson L. Con: routine use of brain perfusion techniques is not supported in deep hypothermic circulatory arrest. J Cardiothorac Vasc Anesth. 2017;31:1905-9.

30. Leshnower BG, Rangaraju S, Allen JW, Stringer AY, Gleason TG, Chen EP. Deep hypothermia with retrograde cerebral perfusion versus moderate hypothermia with antegrade cerebral perfusion for arch surgery. Ann Thorac Surg. 2019; 107:1104-10. 
31. Boeckxstaens CJ, Flameng WJ. Retrograde cerebral perfusion does not perfuse the brain in nonhuman primates. Ann Thorac Surg. 1995;60:318-9.

32. Galyfos G, Sianou A, Filis K. Cerebral hyperperfusion syndrome and intracranial hemorrhage after carotid endarterectomy or carotid stenting: a meta-analysis. $J$ Neurol Sci. 2017;381:74-82.

33. Halstead JC, Meier M, Wurm M, Zhang N, Spielvogel D, Weisz D, et al. Optimizing selective cerebral perfusion: deleterious effects of high perfusion pressures. J Thorac Cardiovasc Surg. 2008;135:784-91.

34. Zaninovich OA, Ramey WL, Walter CM, Dumont TM. Completion of the circle of Willis varies by gender, age, and indication for computed tomography angiography. World Neurosurg. 2017;106:953-63.

35. Hori D, Brown C, Ono M, Rappold T, Sieber F, Gottschalk A, et al. Arterial pressure above the upper cerebral autoregulation limit during cardiopulmonary bypass is associated with postoperative delirium. Br J Anaesth. 2014;113:1009-17.

36. Hori D, Max L, Laflam A, Brown C, Neufeld KJ, Adachi H, et al. Blood pressure deviations from optimal mean arterial pressure during cardiac surgery measured with a novel monitor of cerebral blood flow and risk for perioperative delirium: a pilot study. J Cardiothorac Vasc Anesth. 2016;30:606-12.
37. Croughwell N, Smith LR, Quill T, Newman M, Greeley W, Kern F, et al The effect of temperature on cerebral metabolism and blood flow in adults during cardiopulmonary bypass. J Thorac Cardiovasc Surg. 1992;103: 549-54.

38. Ko TS, Mavroudis CD, Baker WB, Morano VC, Mensah-Brown K, Boorady TW, et al. Non-invasive optical neuromonitoring of the temperaturedependence of cerebral oxygen metabolism during deep hypothermic cardiopulmonary bypass in neonatal swine. J Cereb Blood Flow Metab. 2020;40:187-203.

39. Kleiser S, Nasseri N, Andresen B, Greisen G, Wolf M. Comparison of tissue oximeters on a liquid phantom with adjustable optical properties. Biomed Opt Ex press. 2016;7:2973-92

Key Words: antegrade cerebral perfusion, brain imaging, cerebral blood flow, diffuse correlation spectroscopy, hypothermic circulatory arrest, near-infrared spectroscopy, retrograde cerebral perfusion 


\section{APPENDIX 1 \\ Frequency-Domain Near-Infrared Spectroscopy (FDNIRS)-Diffuse Correlation Spectroscopy (DCS) Device}

DCS and FDNIRS detectors acquire data in parallel, with the DCS laser at $850 \mathrm{~nm}$ always on and the 8 FDNIRS lasers (wavelengths ranging from 670 to $830 \mathrm{~nm}$ ) turned on sequentially in rapid succession $(10-\mathrm{Hz}$ cycle with each laser on for 12 milliseconds). ${ }^{1}$ In patients 1,5 , and 8 , the DCS operated at $2 \mathrm{~Hz}$. In all other patients, the device operating software was updated, and DCS was run at $10 \mathrm{~Hz}$. Crosstalk between the DCS and FDNIRS components is eliminated by optical filters in front of the detectors. To comply with the American National Standards Institute's standards, the DCS laser power was set at below $34 \mathrm{~mW}$, the FDNIRS laser power between 2 and $3 \mathrm{~mW}$, and the light at the probe was diffused over an area $>1 \mathrm{~mm}$. The FDNIRS system needs to be calibrated to account for different requirements for detector gains and fiber transmission at different distances (farther distances require higher gain). For the 8 patients measured with FDNIRS, we calibrated the FDNIRS detectors using 3 calibration blocks of known-optical properties immediately after data collection. Measurements in patient 2 were done with a DCS-only device with the same design and laser as the DCS portion of the MetaOx system, but with only 4 photon-counting detectors, as described in a study by Selb and colleagues. ${ }^{2}$

\section{Optical Probe}

Light sources and detectors from the device were connected via fiber optics to a soft rubbery 3-dimensional printed probe attached to the patient's head. All of the fibers at the probe end were terminated with prisms to allow for a low probe profile. For light transmission to the patient, we used a single-fiber cable that included the fiber bundle from the FDNIRS lasers and a $200-\mu \mathrm{m}$ multimode fiber from the DCS laser. One single-mode fiber located at $5 \mathrm{~mm}$ from the source collected the short separation DCS light. Four fiber bundles at distances of 2, 2.5, 3, and $3.5 \mathrm{~cm}$ from the source collected photons back to the FDNIRS detectors. In 1 patient (9) $1.5,2,2.5$, and $3 \mathrm{~cm}$ distances were used for FDNIRS. Fiber bundles at 2.5 and $3 \mathrm{~cm}$ also included DCS single-mode detection fibers for a colocalized acquisition (Figure 2). The probe was attached with tape to the patient's forehead, and to shield from ambient light, a soft black craft cloth was taped over the probe. In most patients, the optical probe was positioned on the right forehead. In 3 patients $(2,6,11)$, cerebral oximetry and electroencephalography were placed on the right side of the forehead in a way that did not leave enough room for the optical probe, so we placed the probe on the left side.

\section{FDNIRS Data Preprocessing}

The FDNIRS data had interference from the hospital INVOS cerebral oximeter, which had to be removed during preprocessing. The INVOS oximeter employs $730 \mathrm{~nm}$ and $810 \mathrm{~nm}$ LEDs, which are switched on and off at $<30 \mathrm{~Hz}$, whereas our FDNIRS employs 8 wavelengths turned on in sequence at $10 \mathrm{~Hz}$ per cycle. The optical cross-talk of between the 2 devices results in spurious peaks in the FDNIRS AC and phase shift signals, which appear at different wavelengths and different times throughout data collection. We used Fourier analysis to find and discard contaminated data segments, typically lasting under 1 minute. Specifically, in 6 patients $(3,6,7,9-11)$, we discarded up to $10 \%$ of each FDNIRS raw data due to the interference. We linearly interpolated across the discarded periods to obtain continuous AC and phase time traces. The raw signal for one of these patients is shown in Figure E1. In patients 3, 6 , and 11 we didn't use the data from the $3.5-\mathrm{cm}$ separation because the INVOS interference was too strong and to calculate optical properties and hemoglobin parameters we use only 2-, 2.5-, and 3-cm source-detector separations. Because the INVOS interference only affected $0-3$ of 8 wavelengths at any given time, and in principle 2 wavelengths are sufficient to estimate oxy and deoxyhemoglobin ( $\mathrm{HbO}$ and $\mathrm{HbR}$, respectively), these artifacts did not affect the final hemoglobin concentration and oxygen saturation $\left(\mathrm{SO}_{2}\right)$, and for these quantities we were able to recover continuous time traces.

In patients 4 and 12, our probe was very close to the hospital oximeter's probe, which resulted in a stronger interference, affecting longer segments of data and up to 4 wavelengths at a time. In these 2 subjects, we had to discard all the data at 3 and $3.5 \mathrm{~cm}$, and at 2 and $2.5 \mathrm{~cm}$ we either discarded or interpolated $30 \%$ of each remaining raw data. So, for these 2 patients, we were only able to calculate discrete optical properties and hemoglobin parameters at sparse timepoints. An example of the stronger interference is shown in Figure E2.

Because the DCS light is so much stronger (DCS laser $\sim 34 \mathrm{~mW}$ vs FDNIRS lasers $\sim 2 \mathrm{~mW}$ ) and coherent, the INVOS noncoherent light added very little background noise to the DCS data and had no effect on the autocorrelation function results.

The doctors' occasional manipulations of the patient's head and adjustments of the hospital electroencephalography and NIRS probes produced artifacts in the collected data and a very small percent $(<0.1 \%)$ of both DCS and FDNIRS data had to be discarded.

Finally, after artifact removal in preprocessing, we smoothed the $10 \mathrm{~Hz}$ FDNIRS AC and phase shift data using a 50-point averaging window, down-sampling to $0.2 \mathrm{~Hz}$. 


\section{Calculation of Optical Properties and Hemoglobin Oxygen Saturation With FDNIRS}

After preprocessing, the raw FDNIRS data were analyzed using the frequency domain multidistance method $^{3}$ to compute the optical properties of the measured tissue at each wavelength. Following this method, the $\mathrm{AC}$ and phase shift slopes versus distance were used to quantify the absorption and scattering coefficients, $\mu_{\mathrm{a}}$ and $\mu_{\mathrm{s}}{ }_{\mathrm{s}}$, respectively. After calculating $\mu_{\mathrm{a}}$ and $\mu_{\mathrm{s}}{ }_{\mathrm{s}}$ at all wavelengths, we used the absorption coefficients at 5 or more wavelengths to estimate oxy and deoxy hemoglobin concentrations ( $\mathrm{HbO}$ and $\mathrm{HbR}$, respectively) assuming a constant water fraction in tissue of 0.75. Total hemoglobin concentration (HbT) and hemoglobin $\mathrm{SO}_{2}$ were derived from $\mathrm{HbO}$ and $\mathrm{HbR}$ concentrations using the following equations:

$$
\mathrm{HbT}=\mathrm{HbO}+\mathrm{HbR}, \mathrm{SO}_{2}=\mathrm{HbO} / \mathrm{HbT} .
$$

Quantifying the $\mathrm{SO}_{2}$ changes during circulatory arrests. We calculated the difference in $\mathrm{SO}_{2} 1$ minute before $\mathrm{HCA}$ and 1 minute right before reperfusion. The $\mathrm{SO}_{2}$ drop rate was calculated by dividing the total drop by the length of the HCA, as recorded by the clinical team.

\section{DCS Data Analysis}

During preprocessing, the DCS intensity autocorrelation functions $\left(\mathrm{g}_{2}\right)$ were smoothed by taking the median of a 10point window for patients 1,5 , and 8 (acquired at $2 \mathrm{~Hz}$ ), and a 50-point window for all other patients (acquired at $10 \mathrm{~Hz}$ ) to achieve a final sampling rate of $0.2 \mathrm{~Hz}$ in all patients.

We analyzed the DCS data using the semi-infinite medium boundary condition for correlation diffusion equation. ${ }^{3}$ In all subjects, we reported data at 25 -mm separation except for patient 2, for which we only had the measure at $30 \mathrm{~mm}$.

Optical properties at $850 \mathrm{~nm}$ are needed to calculate blood flow index $\left(\mathrm{BF}_{\mathrm{i}}\right)$. For 6 of the 12 patients, we had continuous FDNIRS optical properties at 5 to 8 wavelengths and were able to quantify the absorption and reduced scattering coefficient at $850 \mathrm{~nm}$ by interpolation. For these subjects we used these time-varying $\mu_{\mathrm{a}}$ and $\mu_{\mathrm{s}}{ }^{\prime}$ values to calculate absolute values of cerebral blood flow index $\left(\mathrm{CBF}_{\mathrm{i}}\right)$ and cerebral metabolic rate of oxygen (index) $\left(\mathrm{CMRO}_{2 \mathrm{i}}\right.$; described in later section "Quantification of Cerebral Metabolic Rate of Oxygen and Its Relationship With Temperature"). Since in 4 patients we didn't have FDNIRS data and tissue optical properties, and in 2 patients we only had intermittent FDNIRS data and optical properties, in all subjects, for the calculation of relative $\mathrm{CBF}_{\mathrm{i}}$ changes with $\mathrm{HCA}$, we used fixed optical properties. Specifically, we used $\mu_{\mathrm{a}}=0.11 \pm 0.03 \mathrm{~cm}^{-1}$ and $\mu_{\mathrm{s}}^{\prime}=8.5 \pm 1.4 \mathrm{~cm}^{-1}$, obtained by averaging absorption and scattering across the whole surgery, and performing a grand average across the 8 patients with FDNIRS measurements.
For each subject, we quantified the $\mathrm{CBF}_{\mathrm{i}}$ drops at $\mathrm{HCA}$ by calculating the ratio of $\mathrm{CBF}_{\mathrm{i}}$ between the duration of $\mathrm{HCA}$ and the pre-HCA values. The pre-CA values were obtained by averaging 5 minutes of $\mathrm{CBF}_{\mathrm{i}}$ data immediately before the HCA onset, with one exception, patient 2, in whom we had to use a 2-minute period because of a gap in the data acquisition between 4 and 2 minutes before HCA. The during-HCA values were obtained by averaging $\mathrm{CBF}_{\mathrm{i}}$ from 1 minute into HCA to the HCA stop time.

We also quantified the $\mathrm{CBF}_{\mathrm{i}}$ overshoot at reperfusion post-HCA as the ratio between the value at the greatest reperfusion peak (there were multiple peaks in some cases where the surgeon asked to have the pump started and stopped several times) and the resting value several minutes after the overshoot.

\section{Use of Fixed Versus Actual Optical Properties for DCS CBF $_{\mathbf{i}}$ Calculations}

In the 8 patients with FDNIRS, we evaluated the error due to the assumption of fixed optical properties in calculating $\mathrm{CBF}_{\mathrm{i}}$ and $\mathrm{CBF}_{\mathrm{i}}$ relative changes versus using the actual measured optical properties. As described in Irwin and colleagues, ${ }^{5}$ absolute $\mathrm{CBF}_{\mathrm{i}}$ values are strongly affected by $\mu_{\mathrm{s}}{ }_{\mathrm{s}}$, and to a lesser extent by $\mu_{\mathrm{a}}$. Using fixed instead of measured optical properties induced an average $16 \pm 11 \%$ change in the absolute $\mathrm{CBF}_{\mathrm{i}}$ values.

Because relative changes in $\mu_{\mathrm{s}}{ }^{\prime}$ during surgery were relatively small (the maximum change across the entire procedure was $13 \pm 6 \%$ across subjects, which, in most subjects, happened after the patient was taken off of $\mathrm{CPB}$ ), the use of fixed versus actual optical properties had little effect on the relative $\mathrm{CBF}_{\mathrm{i}}$ changes during versus pre- or post-HCA results. By comparing fixed versus measured optical properties, we found that the ratios of $\mathrm{CBF}_{\mathrm{i}}$ during versus preHCA across the 8 subjects changed by $6 \pm 6 \%$, the ratios of post-HCA overshoot changed by $2 \pm 1 \%$, and that the difference in the relative $\mathrm{CBF}_{\mathrm{i}}$ through the entire measurement was only $4 \pm 5 \%$.

\section{Quantification of Cerebral Metabolic Rate of Oxygen and Its Relationship With Temperature}

To calculate oxygen consumption, we used the following equation: $\mathrm{CMRO}_{2 i}=\frac{H G B}{M W_{H b}} * C B F_{i}\left(\mathrm{SaO}_{2}-\mathrm{SO}_{2}\right),{ }^{6}$ where HGB is the patient's hemoglobin concentration in the blood (units $\mathrm{g} / \mathrm{dL}$ ) and $\mathrm{MW}_{\mathrm{Hb}}$ is the molecular weight of hemoglobin $(65,400 \mathrm{~g} / \mathrm{Mol})$. HGB was collected at 30-minute intervals by the clinical team, and we linearly interpolated over the points to get a continuous variable. In all 8 patients, arterial oxygenation was maintained at $100 \%$ by the cardiopulmonary bypass during cooling and rewarming. As described previously, $\mathrm{SO}_{2}$ was measured with the FDNIRS and $\mathrm{CBF}_{\mathrm{i}}$ was calculated using actual optical properties. 
For each patient, $\mathrm{CMRO}_{2 \mathrm{i}}$ averages for cooling and rewarming periods were calculated separately. We averaged $\mathrm{CMRO}_{2}$ values over $2^{\circ} \mathrm{C}$ associated with up to 7 evenly spaced temperature windows, from $20.5^{\circ} \mathrm{C}$ to $34.5^{\circ} \mathrm{C}$. We normalized each patient's $\mathrm{CMRO}_{2 \mathrm{i}}$ values with respect to the average $\mathrm{CMRO}_{2 \mathrm{i}}$ in the window between $34.5^{\circ} \mathrm{C}$ $36.5^{\circ} \mathrm{C}$, taken during each patient's rewarming period. Data with significant artifacts in $\mathrm{CBF}_{\mathrm{i}}$ caused by $\mathrm{CPB}$ flow rate adjustments were excluded from calculations. To estimate the $\mathrm{CMRO}_{2 \mathrm{i}}$ relationship with temperature, we fit a linear regression for all patients' normalized $\mathrm{CMRO}_{2 \mathrm{i}}$ (log scale) with respect to the mean temperature windows.

\section{Other Parameters of Interest at Circulatory Arrests}

We also quantified group averages for drops in the INVOS regional oxygen saturation $\left(\mathrm{rSO}_{2}\right.$; Table E1). The median INVOS $\mathrm{rSO}_{2}$ right side drop was $23 \%$ (range, $18 \%-37 \%$ ) in HCA-only, $12 \%$ in RCP, and $0 \%$ (range, $-2.5 \%$ to $9 \%$ ) in ACP cases. The median INVOS $\mathrm{rSO}_{2}$ left side drop was
$20 \%$ (range, $23 \%-38 \%$ ) in HCA-only, $7 \%$ in RCP, and $5 \%$ (range, $3 \%-23 \%$ ) in ACP cases.

\section{References}

1. Carp SA, Farzam P, Redes N, Hueber DM, Franceschini MA. Combined multidistance frequency domain and diffuse correlation spectroscopy system with simultaneous data acquisition and real-time analysis. Biomed Opt Express. 2017;8:3993-4006.

2. Selb J, Wu K-C, Sutin J, Lin P-YI, Farzam P, Bechek S, et al. Prolonged monitoring of cerebral blood flow and autoregulation with diffuse correlation spectroscopy in neurocritical care patients. Neurophotonics. 2018;5: 45005 .

3. Durduran T, Choe R, Baker WB, Yodh AG. Diffuse optics for tissue monitoring and tomography. Rep Prog Phys. 2010;73:076701.

4. Wolthuis R, van Aken M, Fountas K, Robinson, Bruining HA, Puppels GJ. Determination of water concentration in brain tissue by Raman spectroscopy. Anal Chem. 2001;73:3915-20.

5. Irwin D, Dong L, Shang Y, Cheng R, Kudrimoti M, Stevens SD, et al. Influences of tissue absorption and scattering on diffuse correlation spectroscopy blood flow measurements. Biomed Opt Express. 2011;2:1969-85.

6. Roche-Labarbe N, Carp SA, Surova A, Patel M, Boas DA, Grant PE, et al. Noninvasive optical measures of $\mathrm{CBV}, \mathrm{StO}(2), \mathrm{CBF}$ index, and $\mathrm{rCMRO}(2)$ in human premature neonates' brains in the first six weeks of life. Hum Brain Mapp. 2010;31: $341-52$. 


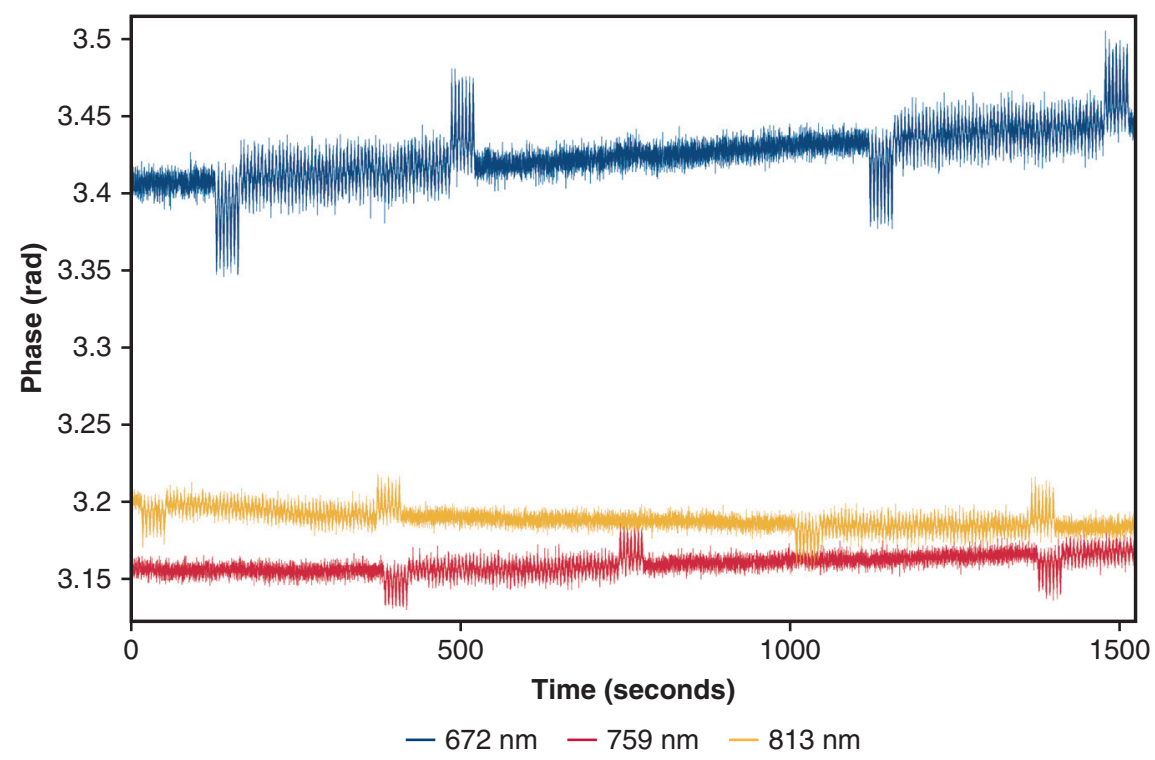

FIGURE E1. FDNIRS raw phase data at 672,759 , and $813 \mathrm{~nm}$ and $3 \mathrm{~cm}$ source-detector separation in patient 6 . The interference from the hospital INVOS oximeter lasts several minutes but is only strong enough to affect our data during the start and end small jumps that have an amplitude of approximately 0.05 radians in the raw signal. Each of these jumps is roughly 40 seconds wide, easy to analytically detect, and remove.

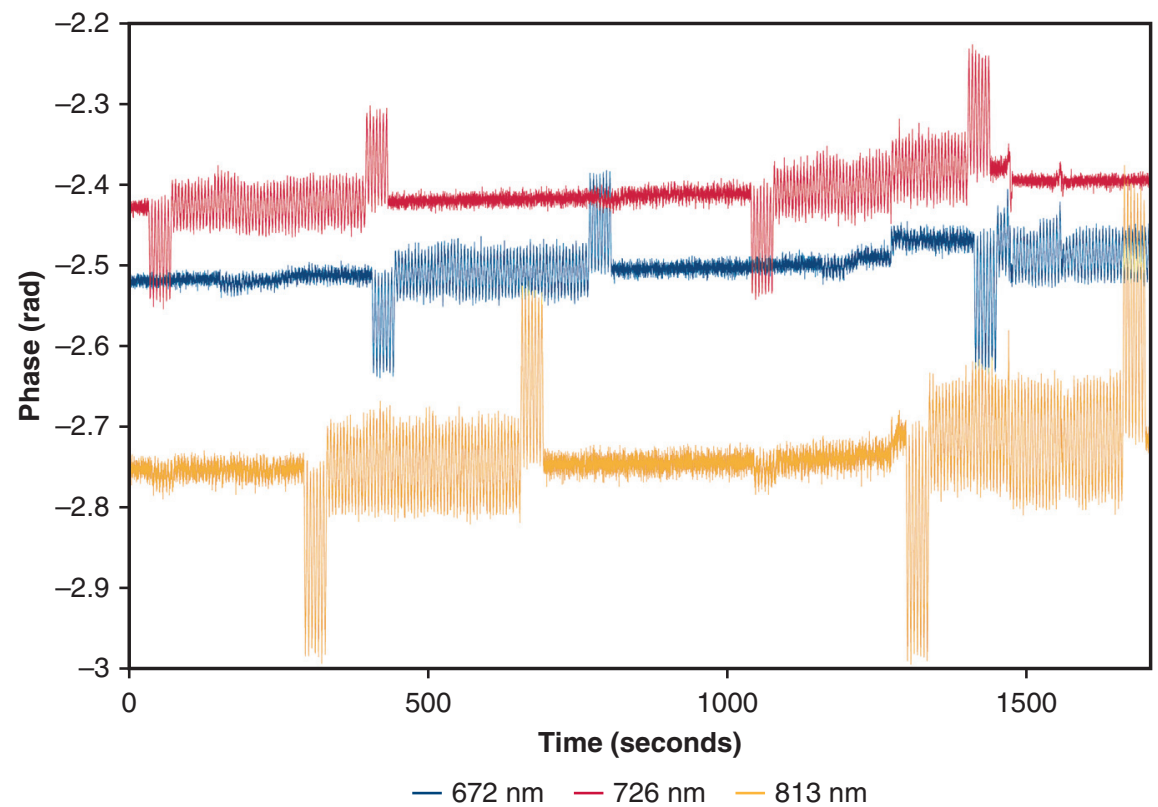

FIGURE E2. FDNIRS raw phase data at 672,726 , and $813 \mathrm{~nm}$ and detector at $2.5 \mathrm{~cm}$ from the source, from patient 12 , showing the strong interference of the hospital INVOS oximeter. Here, the interference during the entire 5- to 7-minute long period is strong enough to affect our data. This combined with the overlap across wavelengths makes potential interpolation algorithms more difficult to standardize. 
HCA with ACP (Pt.10)
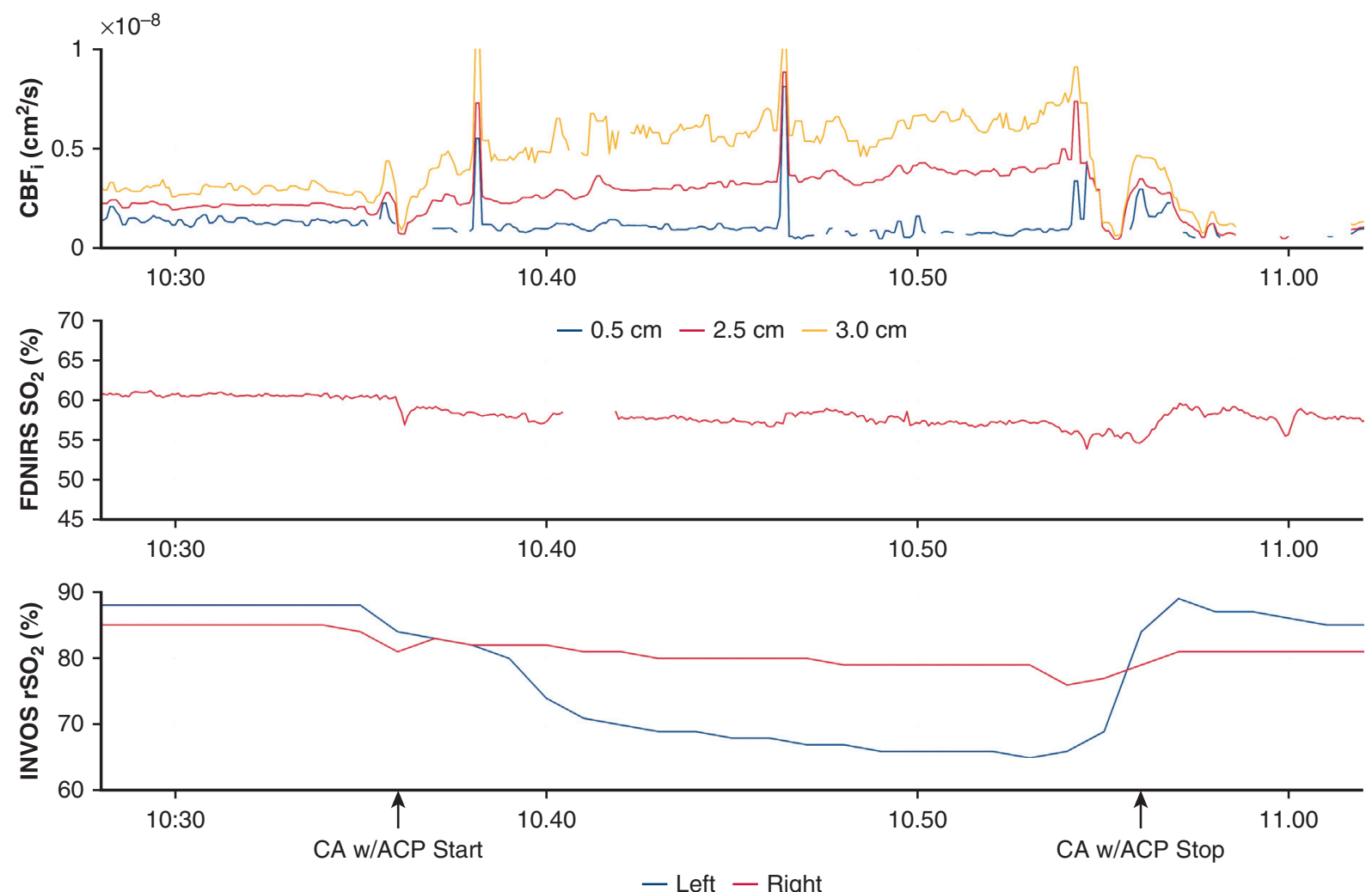

FIGURE E3. $\mathrm{CBF}_{\mathrm{i}}$, hemoglobin $\mathrm{SO}_{2}$, and the hospital INVOS oximeter regional $(\mathrm{r}) \mathrm{SO}_{2}$ time-traces around a $\mathrm{HCA}$ with $\mathrm{ACP}$ in patient \#10. CBF $\mathrm{i}$ and FDNIRS $\mathrm{SO}_{2}$ are measured on the right side, whereas INVOS has bilateral measurements. Note that although the right-side FDNIRS and INVOS oxygen saturation report relatively steady levels, the left INVOS $\mathrm{rSO}_{2}$ drops throughout the HCA, suggesting decreased blood flow delivery to that hemisphere, similar to the RCP or HCA-only cases. This may be caused by an incomplete circle of Willis. $\mathrm{CBF}_{\mathrm{i}}$ measured on the right side supports this hypothesis since increasing perfusion pressure from the clinical team only served to increase $\mathrm{CBF}_{\mathrm{i}}$ through $\mathrm{HCA}$, with the long separations $\mathrm{CBF}_{\mathrm{i}}$ increasing to more than $200 \%$ of the pre-HCA levels. Artifacts in $\mathrm{CBF}_{\mathrm{i}}$ through $\mathrm{HCA}$ are from a clinician pressing on the probe mid-procedure. $C B F_{i}$, Cerebral blood flow index; $\mathrm{HCA}$, hypothermic circulatory arrest; $\mathrm{ACP}$, antegrade cerebral perfusion; $\mathrm{FDNIRS}$, frequency domain near-infrared spectroscopy; $\mathrm{SO}_{2}$, oxygen saturation; $r \mathrm{SO}_{2}$, regional oxygen saturation. 
TABLE E1. Group-level quantification of $\mathrm{CBF}_{\mathrm{i}}$, hemoglobin $\mathrm{SO}_{2}$, the hospital INVOS oximeter, and MAP behavior with circulatory arrests

\begin{tabular}{|c|c|c|c|c|c|c|c|c|c|}
\hline $\begin{array}{c}\text { Perfusion } \\
\text { group }\end{array}$ & $\begin{array}{c}\text { CBF }_{\mathrm{i}} \\
\text { drop from } \\
\text { baseline, } \%\end{array}$ & $\underset{\text { overshoot, \%* }}{\text { CBF }_{\mathbf{i}}}$ & $\begin{array}{l}\text { SO }_{2} \text { baseline } \\
\text { (FDNIRS, \%) }\end{array}$ & $\begin{array}{c}\mathrm{SO}_{2} \text { drop } \\
(\text { FDNIRS, \%) }\end{array}$ & $\begin{array}{l}\text { INVOS left } \\
\text { baseline, } \%\end{array}$ & $\begin{array}{l}\text { INVOS left } \\
\text { drop, } \%\end{array}$ & $\begin{array}{l}\text { INVOS right } \\
\text { baseline, } \%\end{array}$ & $\begin{array}{l}\text { INVOS right } \\
\text { drop, } \%\end{array}$ & $\begin{array}{c}\text { MAP } \\
\text { baseline, } \\
\text { mm Hg }\end{array}$ \\
\hline HCA-only & $95 \pm 1 \%$ & $240 \pm 50$ & $59 \pm 7 \%$ & $18 \pm 4 \%$ & $77 \pm 7 \%$ & $27 \pm 10 \%$ & $70 \pm 0.6 \%$ & $26 \pm 10 \%$ & $64 \pm 4$ \\
\hline $\mathrm{RCP}$ & $91 \pm 3 \%$ & $250 \pm 70$ & $70.2 \% \dagger$ & $13 \% \dagger$ & $95 \% \dagger$ & $7 \% \dagger$ & $95 \% \dagger$ & $12 \% \dagger$ & $64 \pm 7$ \\
\hline $\mathrm{ACP}$ & $-12 \pm 28 \%$ & N/A & $59 \pm 14 \%$ & $3 \pm 2 \%$ & $91 \pm 3 \%$ & $10 \pm 11 \%$ & $83 \pm 7 \%$ & $2 \pm 6 \%$ & $73 \pm 28$ \\
\hline
\end{tabular}

Baseline is equivalent to the pre-HCA window defined for $\mathrm{CBF}_{\mathrm{i}}$ and $\mathrm{SO}_{2}$ previously. $\mathrm{CBF}_{\mathrm{i}}$ overshoot is calculated by comparing the maximum value reached at reperfusion with the mean value reached 1-3 minutes after reperfusion. All data are expressed as mean \pm standard deviation. $C B F_{i}$, Cerebral blood flow index; $\mathrm{SO}_{2}$, oxygen saturation; $F D N I R S$, frequency-domain near-infrared spectroscopy; $M A P$, mean arterial pressure; $H C A$, hypothermic circulatory arrest; $R C P$, retrograde cerebral perfusion; $A C P$, antegrade cerebral perfusion. *The percentage here represents the overshoot's value as a percentage of the baseline value. Hence, an overshoot that is twice as high as the baseline would have a value of $200 \%$. † Standard deviation not estimated since $\leq 2$ patients had this measurement. 